\title{
EL RECONOCIMIENTO Y CONTENIDO INTERNACIONAL DEL ACCESO A LA INFORMACIÓN PÚBLICA COMO DERECHO FUNDAMENTAL
}

\author{
LORENZO COTINO HUESO \\ Catedrático de Derecho Constitucional \\ Universidad de Valencia ${ }^{1}$
}

\begin{abstract}
SUMARIO
I. El reconocimiento del acceso a la información como derecho fundamental en el ámbito mundial y de América Latina. II. La doble vía del reconocimiento por el Consejo de Europa y el TEDH en 2016 y la UE. III. Los titulares, los sujetos obligados y la información objeto del derecho. IV. El principio de máxima transparencia, el contenido del derecho de acceso a la información y las obligaciones que comporta. V. Garantías a su ejercicio: un acceso sin interés legítimo, sin barrerras, con agilidad, sencillez, sin trabas económicas y con recursos efectivos administrativos y judiciales. VI. Los requisitos de los límites al derecho de acceso y el conflicto con la protección de datos, especialmente en la UE. VII. Para concluir, la necesaria interiorización del derecho como fundamental en España
\end{abstract}

Que el derecho de acceso a la información pública se ha conformado internacionalmente como un derecho fundamental, no hay duda. Que ello aún no se ha consolidado en Europa y especialmente en España, tampoco. Entiendo que el atractivo de este proceso de consolidación como derecho y fundamental va más allá del interés concreto por este nuevo e importante derecho para nuestras sociedades democráticas. $\mathrm{Y}$ este proceso de emergencia de un nuevo derecho

1 El presente estudio es producto de investigación en el marco del Grupo en Derecho Público y TIC, de la Universidad Católica de Colombia, dentro de la investigación "Análisis de la ley de transparencia y acceso a la información pública nacional»(2016). Asimismo, se realiza en el marco del Proyecto español del Ministerio de Economía «El avance del Gobierno Abierto. Régimen jurídico constitucional de la implantación de políticas de transparencia, acceso a la información, datos abiertos, colaboración y participación especialmente a través de las TIC y del gobierno electrónico» DER2015-65810-P. 
fundamental ha sido esencialmente impulsado por su paulatino reconocimiento internacional y supranacional. El análisis de este proceso es objeto de las siguientes páginas para, a continuación, destilar los elementos básicos de la estructura de este derecho: sujetos, obligados, objeto del derecho, facultades y obligaciones concretas que se derivan del mismo y elementos de garantía y sus restricciones.

Excede al presente estudio el análisis comparado de este derecho ${ }^{2}$ y el muy interesante proceso de constitucionalización interna en muchos países del mundo ${ }^{3}$. De igual modo, y pese al máximo interés de la cuestión, no se aborda ni el tratamiento jurídico constitucional ni legal del derecho de acceso a la información en España. Estudios sobre la cuestión no faltan ${ }^{4}$, tampoco de quien suscribe. Ahora bien, una de las intenciones obvias de este estudio es asentar las bases para el tratamiento del acceso a la información como derecho fundamental en España. Ello ha de darse en razón del reconocimiento internacional y europeo del acceso a la información y la obligatoriedad de interpretación constitucional por mor del artículo 10. $2^{\circ} \mathrm{CE}$ que conlleva la iusfundamentalidad del derecho en nuestro país. De un lado, el acceso a la información integra la libertad de expresión e información, reconocida como fundamental en España. Así, tanto en el ámbito de Naciones Unidas cuanto la muy reciente STEHD de 8 de noviembre de 2016 caso Magyar Helsinki Bizottság contra Hungría. Del otro lado la fundamentalidad del acceso a la información pública en España se deriva del reconocimiento del derecho de acceso a los documentos en el artículo 42 de la Carta de los Derechos Fundamentales de la Unión Europea (CDFUE). Ello tiene una importante aunque limitada proyección interna en nuestro país. Aunque exceda el marco de esta investigación, sí que se da algún comentario respecto de una y otra vías de fundamentalidad del derecho de acceso en España.

2 Respecto del reconocimiento comparado del derecho de acceso a la información recientemente cabe destacar [s.a]: Estudio comparado sobre normativa internacional en materia de derecho de acceso a la información pública, INAP, Madrid, 206. Para un seguimiento mundial de las leyes de acceso, cabe destacar la codificación de 2.500 páginas realizada por Perlingeiro, R.: Information Access Laws in the World: Compilation of National Laws, Legislative Bills and Model Codes on the Right of Access to the Official Information, Niterói, Eduff, 2014.

3 A este respecto, cabe destacar dos estudios: Peled, R. Rabin, Y.: "The Constitutional Right to Information», Columbia Human Rights Review, Volume 42(2) (2010); CENTRE FOR LAw AND DeMOCRACY's Entrenching RTI: An Analysis of Constitutional Protections of the Right to Information, 2012, en especial pp. 12 y ss.

4 Son ya muchas las obras de referencia en la materia en nuestro país que por extensión no cabe citar. Me permito destacar singularmente los trabajos y obras coordinadas de Guichot Reina, Fernández Ramos o Blanes Climent. También los estudios de Villaverde, Rams, De la Nuez, Sánchez de Diego o Gutiérrez David. De igual modo, las obras coordinadas por García Macho y posterior a la Ley 19/2013, la editada por Fernández Salmerón, M. y Valero Torrijos, J.; por Moretón Toquero; por Wences y otros; por Bermejo Latre y Castel o la de Piñar Mañas. Y de reciente aparición el comentario editado por Troncoso de reciente aparición. Por cuanto a los diversos estudios sobre el tema de quien suscribe, puede accederse a los mismos en la web referida al inicio. 


\section{EL RECONOCIMIENTO DEL ACCESO A LA INFORMACIÓN COMO DERECHO FUNDAMENTAL EN EL ÁMBITO MUNDIAL Y DE AMÉRICA LATINA}

\section{El reconocimiento del derecho de acceso a la información a partir del derecho a buscar información, la acción de la ONG «Artículo 19» y los relatores de la libertad de expresión}

En un largo proceso, el acceso a la información se ha ido conformando como un derecho subjetivo a partir del derecho a buscar información que está integrado en la libertad de expresión e información de los arts. 19 de la DUDH y del PIDCP. Estas libertades expresamente incluyen el derecho a «investigar y recibir informaciones» (art. 19 DUDH) y «la libertad de buscar, recibir y difundir informaciones e ideas de toda índole» (art.19.2 PIDCP). Estas libertades se habían reconocido especialmente a los periodistas 5 . En la Commonwealth de manera pionera se trabajó el acceso a la información desde $1980^{6}$.

Aunque ya existían avances en materia de acceso a la información pública en medio ambiente y una creciente atención en la UE, hay que destacar la importante acción de la ONG «Artículo 19, Campaña Mundial para la Libertad de Expresión». En 1995 impulsó los Principios de Johannesburgo, que están en el origen de no pocas declaraciones y resoluciones internacionales mundiales y regionales. De igual modo son un referente sus Principios sobre la Legislación de 1999, en adelante Principios de la ONG «Artículo 19». Tales principios traían causa de la diversa normativa y jurisprudencia supranacional, nacional y sectorial. Asimismo hay que tener en cuenta la muy detallada ley modelo de acceso a la información a partir de tales principios. En el marco de dicha ONG hay que seguir los estudios liderados por $\mathrm{Mendel}^{7}$ para UNESCO y otras organizaciones, que han sido sin duda los más exhaustivos análisis sobre el reconocimiento internacional de este derecho, si bien hasta $2008^{8}$. Desde entonces coordina el ránking de normativas transparencia Global Right to Information Rating (www.rti-rating. org/). Entre los análisis posteriores ${ }^{9}$ destaca, precisamente el muy recientemente

5 Así, en Comunicación No 633/1995, Gauthier c. el Canadá, dictamen aprobado el 7 de abril de 1999, párr. 13.4.

6 Declaración de Ministros Jurídicos de la Mancomunidad en Barbados en 1980.

7 Desde 2010 dicha persona dirige el Center for Law and Democracy, también vinculado a la transparencia http://www.law-democracy.org/live/

8 Mendel, T.: The Public's Right to Know: Principles on Freedom of Information Legislation, Londres, UNESCO, junio de 1999 y más reciente, MEndel, T., Freedom of Information: A Comparative Legal Survey, UNESCO, ( $1^{\circ}$ ed. Nueva Delhi, 2003 y 2 a , París, 2008). También en español, Libertad de información: comparación jurídica, 2. ed., UNESCO, París, 2008, acceso en https://goo.gl/mJDdoy. En paralelo, hasta 2007 hay un muy completo estudio OEA: Estudio especial sobre el derecho de acceso a la información, Washington, 2007, http://goo.gl/ldNdll

9 El análisis internacional más completo se da en AA.VV. Transparencia y acceso a la información pública, XIII Informe de la FIO, Trama, Madrid, 2015, pp. 23-58, acceso en https://goo.gl/ldsGeW 
realizado por la STEHD de 8 de noviembre de 2016 caso Magyar (respecto del ámbito internacional, § 35-43).

En marzo de 1993 la Comisión de Derechos Humanos de la ONU creó la Relatoría Especial de la ONU para la Libertad de Opinión y Expresión ${ }^{10}$ con la finalidad de determinar el contenido de estas libertades. Y en 1997 le solicitó que profundizase en el derecho a búsqueda de información ${ }^{11}$. Con especial influencia de las acciones de la referida ONG, desde el informe de 1998 se afirmó la «obligación positiva sobre los Estados para asegurar el acceso a la información, particularmente respecto a la información que está en manos del Gobierno» ${ }^{12}$. El Informe de 1999 centró la atención y afirmó el «derecho de acceso a la información en poder del Estado» ${ }^{13}$.

Y la atención aún fue más intensa en el Informe del año $2000^{14}$ que se han dado a llamar, impropiamente, «normas de la ONU». Ahí el acceso a la información fue calificado como derecho fundamental, se delimitaron algunos de sus contenidos y se afirmó lo excepcional de sus limitaciones por ley (\$ 18 y 20).

El 26 de noviembre de 1999, «bajo los auspicios» de esta ONG «Artículo $19 »$, los tres relatores internacionales sobre libertad de expresión adoptaron una declaración conjunta en la que se afirmaba que «Está implícito en la libertad de expresión el derecho del pueblo al acceso abierto a la información y de saber qué es lo que los gobiernos están haciendo para el pueblo; sin esto, la verdad se extinguiría y la participación popular del gobierno permanecería fragmentada.» ${ }^{15}$. El 16 de noviembre de 2000, estos relatores, con otras instituciones públicas y privadas adoptaron en Perú los Principios de Lima sobre derecho de acceso a la información ${ }^{16}$. Estos principios, en buena medida integraban bastantes de los referidos principios de la ONG artículo 19 y tienen especial proyección en Iberoamérica.

En la Commonwealth, tras sus avances desde los años 80, en 1999 se adoptaron los Principios de Libertad de Información recomendando a los miembros el reconocimiento del derecho de acceso a la información pública ${ }^{17}$. Para facilitar al actividad, la Secretaría del Commonwealth adoptó una Ley modelo sobre libertad de

10 Resolución 1993/45, de 5 marzo de 1993.

11 Resolución 1997/27, 11 abril 1997, párrafo 12(d).

12 Informe del Relator Especial, Promoción y protección del derecho a libertad de opinión y expresión, ONU Doc. E/CN.4/1998/40, 28 enero 1998, párrafo 14.

13 Informe del Relator Especial sobre la protección y promoción del derecho a la libertad de opinión y expresión, UN doc. E7CN.4/1999/64, 29 de enero de 1999, pp. 28 y ss.

14 Informe del Relator Especial, Promoción y protección del derecho a libertad de opinión y expresión, ONU Doc. E/CN.4/2000/63, 18 enero 2000, en especial pp. 30 y ss.

15 El Relator Especial de la ONU para Libertad de Opinión y Expresión, el Representante de la OSCE sobre la Libertad de los Medios de Comunicación Social y el Relator Especial de la OEA sobre la Libertad de Expresión http://www.oas.org/es/cidh/expresion/showarticle.asp?artID=141\&lID=2

$16 \mathrm{http}: / /$ www.oas.org/es/cidh/expresion/showarticle.asp? $\operatorname{artID}=158 \&$

17 Reunión de Ministros Jurídicos de la Mancomunidad (Puerto España: 10 mayo 1999). Comunicado de Durban (Durban: Reunión de Jefes de Gobierno de la Mancomunidad, 15 noviembre 1999). 
información en septiembre de $2002^{18}$, antecesora de otras como para iberoamericano. En África, a partir del reconocimiento de la libertad de expresión en la Carta Africana sobre Derechos Humanos y de los Pueblos, 27 de junio de $1981^{19}$, el 23 de octubre de 2002 se afirmó el acceso a la información pública ${ }^{20}$.

De especial importancia fue la Declaración conjunta de los relatores sobre acceso a la información y sobre la legislación que regula el secreto de 6 de diciembre de 2004. Ahí los relatores se asumían en buena medida los principios antes afirmados y se detallaba el contenido y garantías de este derecho. La Declaración conjunta de 9 de diciembre de 2006 subrayó la gran importancia de la SCIDH Claude Reyes de ese mismo año. De igual modo, se invitaba a adoptar políticas de transparencia a los a los bancos y organismos financieros internacionales, organismos públicos internacionales y las organizaciones intergubernamentales, incluyendo la publicidad activa y derecho de acceso, con posibilidad de garantías. Esta Declaración hizo mención a la «Carta de Transparencia para las Instituciones Financieras Internacionales» promovida por la «Iniciativa para la Transparencia Mundial», «GIFT» ${ }^{21}$. Como consecuencia, desde 2009 se impulsaron y fortalecieron las políticas y normativas internas que habían empezado a adoptar por estas entidades desde los años 90.

En África, la Comisión Africana de los Derechos Humanos adoptó en 2010 una resolución a favor del acceso a la información en África, y puso en marcha el proceso de elaboración de un modelo de ley sobre el acceso a la información en África. Promovido por el Relator Especial sobre la libertad de expresión y el acceso a la información de la Comisión Africana de Derechos Humanos y de los Pueblos, culminó con su aprobación en febrero de $2013^{22}$.

\section{El tardío pero importante reconocimiento del derecho por el Comité de Derechos Humanos}

La actuación del Comité de Derechos Humanos respecto del derecho de acceso a la información pública no fue llamativa prácticamente hasta el

18 Doc. $\operatorname{LMM}(02) 6$, acceso en https://goo.gl/3BNrUU

19 Art. 9 (Aprobada el 27/07/1981, durante la XVIII Asamblea de Jefes de Estado y Gobierno de la Organización de la Unidad Africana, reunida en Nairobi, Kenya). https://goo.gl/1NQftO

20 Capítulo IV sobre «Libertad de información», principios básicos del acceso a la información pública. Declaración de Principios sobre Libertad de Expresión de la Comisión Africana, Sesión Ordinaria de la Comisión Africana de Derechos Humanos y de los Pueblos, 17-23/10/2002, Banjul, La Gambia. acceso en inglés en http://www1.umn.edu/humanrts/achpr/expressionfreedomdec.html

21 Se trata de una red de sociedad civil, creada en Georgia, EE.UU., en 2003 Iniciativa Mundial para la Transparencia Fiscal (GIFT) que trabaja con países de todo el mundo para avanzar en la institucionalización de normas globales y mejoras continuas y de calado en el ámbito de la transparencia fiscal, la participación y la rendición de cuentas. http://www.ifitransparency.org

22 Sobre el tema en la institución http://www.achpr.org/instruments/access-information/ El texto de la ley modelo de 2013 https://goo.gl/sP0WIm 
Dictamen del caso Nurbek Toktakunov vs. Kirguistán ${ }^{23}$. Ahí se afirmó categóricamente y por primera vez en una resolución interpretativa el acceso a la información pública como derecho fundamental integrante del artículo 19. $2^{\circ}$ PIDCP ( $\$ 6.2$ y 7) y sus elementos básicos: contenido de la obligación del Estado $(\S 7)$, no necesidad de interés legítimo, titularidad para periodistas y ONG que vigilen el interés público ( $\$ 6.3$ y ss.), necesidad de justificar las excepcionales restricciones del derecho $(\S 7)$. Y cuatro meses después se aprobó la Observación general no 34 de $2011^{24}$ que en sus puntos 18 y 19 elevó al nivel mundial este reconocimiento del derecho de acceso a la información como derecho fundamental ${ }^{25}$. No hay que olvidar el singular valor de interpretación autorizada del artículo 19 que implica la Observación General. El Dictamen del CDN que resuelve el caso Rafael Rodríguez Castañeda vs. México, Comunicación 2202/2012, de 18 de julio de 2013 viene a ratificar el reconocimiento como derecho fundamental por el $\mathrm{CDN}^{26}$.

\section{El reconocimiento del derecho de acceso a la información como integrante de la libertad de expresión en América Latina con la sentencia Claude Reyes de 2006}

Es de interés la evolución del reconocimiento del derecho de acceso a la información como fundamental en el ámbito iberoamericano ${ }^{27}$. La Relatoría Especial para la Libertad de Expresión desde su creación ha prestado una creciente

23 Comunicación ( $\mathrm{n}^{\circ}$ 1470/2006), 28 de marzo de 2011. Toktakunov es un consultor jurídico de una asociación pública de derechos humanos y solicitó saber el número de personas condenadas a la pena capital en Kirguistán.

24 Comité de Derechos Humanos, $102^{\circ}$ período de sesiones, julio de 2011. https://goo.gl/uiQg2w

25 La misma reconoce rotundamente que «el párrafo 2 del art. 19 enuncia un derecho de acceso a la información en poder de los organismos públicos.» (§ 18). Esta OG determina qué información, quiénes son obligados, y reserva este derecho en principio para los medios de comunicación ( $\$ 18$, aunque se prevé la extensión de este colectivo $\S 44$. Igualmente, el $\S 19$ desarrolla las obligaciones concretas y la publicidad activa, la obligación de adecuación legal, que el acceso a la información pública ha de ser fácil y las garantías y recursos $(\$ 18)$.

26 El sujeto pretendía el acceso directo a las papeletas utilizadas y nulas en la elección presidencial. Dicha solicitud fue denegada por el Instituto Federal Electoral. El Comité considera que el acceso a la información incluye toda aquella en poder del estado, y que «los Estados Partes deben hacer todos los esfuerzos para garantizar el acceso fácil, rápida, efectiva y práctica a dicha información (ibíd., §. 19).» (§. 7). No obstante, en el supuesto la denegación estaba amparada por art. 19. 2 PIDCP.

27 Para el ámbito iberoamericano, «América Latina», en AA.VV.: Transparencia y acceso a la información pública, XIII Informe de la FIO, cit. pp. 59-82. OEA: El derecho al acceso a la información pública en las américas. Estándares interamericanos y comparación de marcos legales. Relatoría Libertad de expresión, 2012, [s.l.], OEA/Ser.L/V/II. http://www.cidh.org/relatoria. También CoTINO, L. «El avanzado reconocimiento y regulación del derecho de acceso a la información pública y la transparencia en Iberoamérica (y su brecha con la realidad)», en Cuadernos Manuel Giménez Abad, n. ${ }^{\circ}$ 14, 2017. También, Perlingeiro, R. y Liani, M. y Díaz Madrigal, I.: Princípios sobre o direito de acesso à informação oficial na América Latina, Revista de Investigações Constitucionais, Curitiba, vol. 3 , n. 2, p. 143-197, mayo-agosto 2016. Acceso en: https://ssrn.com/abstract=2755127 
atención a este derecho que ha considerado parte de la libertad de expresión ${ }^{28}$. En cualquier caso la atención la concentra la sentencia de la CIDH en el caso Claude Reyes y Otros v. Chile, de 19 septiembre 2006. Esta sentencia afirmó rotunda y extensamente el acceso a la información pública como contenido del derecho a buscar y recibir información $(\$ 77)^{29}$ y asienta como contenido del derecho subjetivo muchos de los estándares que se habían ido conformando los años anteriores: no necesidad de interés legítimo, derecho a recibir respuesta motivada, «principio de máxima divulgación» por defecto ( $\$ 92)$, motivación y prueba de toda excepción (\$ 95 y 99). Su influencia fue grande, puesto que entre las obligaciones estatales que implica este derecho se afirmó la adecuación normativa y la garantía judicial (\$ 101). Es más, la condena a Chile suponía además la obligación de capacitación a los órganos, autoridades y agentes públicos ( $\$ 163$ 165). Entre las consecuencias, destacan especialmente los Principios de la OEA de 2008 de acceso a la información ${ }^{30}$ y la Ley Modelo Interamericana sobre Acceso a la Información (Ley modelo), que fue aprobada en junio de 2010 por la Asamblea General ${ }^{31}$. Aunque las nuevas leyes de acceso a la información se dieron con las referencias de México y Perú en 2002, la sentencia y sus derivaciones impulsaron la regulación del acceso a la información pública en los países de la región. Sin perjuicio de las grandes variedades ${ }^{32}$, en general se trata de regulaciones avanzadas, destacando especialmente México ${ }^{33}$.

La sentencia del caso Gomes Lund y otros vs. Brasil de 24 de noviembre de 2010. Consolida el reconocimiento del derecho de acceso a la información, vinculado al tambien nuevo «derecho a la verdad».

28 Así desde segundo Informe Anual a la Comisión en 1999. Hay una especial atención a este derecho en sus informes y desde el año 2003 hasta 2009 se adoptó una resolución anual sobre el tema.

29 «77. Respecto de los hechos del presente caso, la Corte considera que el Art. 13 de la Convención, al garantizar expresamente los derechos de «buscar»y «recibir» «información», protege el derecho de toda persona de solicitar acceso a la información que está bajo el control del Estado, con las excepciones reconocidas bajo el régimen de restricciones en la Convención. Por consiguiente, dicho Art. engloba el derecho de los individuos de recibir dicha información y la obligación positiva del Estado de proporcionarla en tal forma que la persona pueda tener acceso para conocer la información o recibir una respuesta motivada cuando, por alguna razón reconocida por la Convención, el Estado limite el acceso en el caso particular. La información debe ser proporcionada sin necesidad de comprobar interés directo ni relación personal para obtenerla, exceptuándose los casos en los cuales sea aplicable una restricción legítima». ( $\$ 77)$.

30 Principios sobre acceso a la información, aprobados por el Comité Jurídico Interamericano de la OEA 2008. CJI/RES. 147 (LXXIII-O/08).

31 Resolución AG/RES 2607 (XL-O/10) sobre la Ley Modelo.

32 Argentina, Bolivia, Costa Rica, Cuba y Venezuela son los únicos países sin ley de transparencia. Al respecto puede seguirse http://www.oas.org/es/sap/dgpe/ACCESO/mandatos.asp

33 México ocupa el primer lugar del mundo en indicadores de normativa de transparencia del GLOBAL Right to Information Rating (http://www.rti-rating.org/). En la región destacan El Salvador (9. ${ }^{\circ}$ ); Nicaragua y Brasil $\left(22 .^{\circ}\right)$. Un análisis de la normativa de 15 países de la región en «Panorama Nacional», en AA.VV.: Transparencia y acceso a la información pública, XIII Informe de la FIO, cit. pp. 131-380. Asimismo FeRNÁNDEZ DE LARA, A. E.: «Acceso a la información pública en América Latina: Análisis de su diseño institucional en Chile, Colombia y México (2002-2014)», en Revista Debates, Porto Alegre, v. 10, n. 1, p. 111-140, enero-abril, 2016. 


\section{LA DOBLE VÍA DEL RECONOCIMIENTO POR EL CONSEJO DE EUROPA Y LA UNIÓN EUROPEA}

\section{Del inexistente derecho a buscar información al Convenio ${ }^{\circ} 205$ del Consejo de Europa}

El artículo 10 del CEDH reconoce la libertad de expresión, sin referencias al derecho a investigar, recibir o buscar información ${ }^{34}$. Desde los inicios de los 1970 se aprecian resoluciones y recomendaciones para profundizar en la libertad de buscar información y que el artículo $10 \mathrm{CEDH}$ incluya el derecho a buscar y recibir información pública ${ }^{35}$. A inicios de los 80 persisten tales declaraciones ${ }^{36}$. En todo caso, hay que esperar especialmente a los años 2000 para el impulso importante del derecho de acceso a la información. La Recomendación Rec (2002) 2 del Comité de Ministros a los Estados miembros sobre el acceso a los documentos oficiales, de 21 de febrero de $2002^{37}$ estableció unos principios que pasarían a corresponderse en buena medida con los del futuro convenio de 2008. Puede afirmarse que para el año 2002 esta recomendación era bastante avanzada, pero no el Convenio que inspiró años más tarde. En mayo de 2005 el Comité de Ministros del $\mathrm{CdE}^{38}$ recomendó redactar un tratado, que sería el Convenio n ${ }^{\circ} 205$ del CdE sobre el Acceso a los Documentos Públicos se adoptó el 27 de noviembre de $2008^{39}$. No ha tenido mucho éxito y con 8 ratificaciones en 2016 no está en vigor. Este tratado sigue en buena medida la en su día novedosa Recomendación de 21 de febrero de 2002, pero no innova ni incorpora los adelantos que hubo desde entonces en el ámbito internacional o comparado. En todo caso, es el primer tratado internacional en la materia.

\section{El lento y tímido reconocimiento del acceso a la información en el ámbito de la libertad de expresión por el TEDH hasta noviembre de 2016}

La cuestión del acceso a la información pública no ha sido objeto de muchas sentencias del TEDH, ni de la antigua y extinta Comisión de Derechos Humanos ${ }^{40}$.

34 Un extenso análisis se da en los $§ 44-54$ de la STEHD de 8 de noviembre de 2016 caso Magyar.

35 Así, el la Recomendación 582 de la Asamblea Parlamentaria de 23 de enero de 1970 afirma el «deber de las autoridades públicas de hacer accesible la información sobre asuntos de interés público, sujeta a las limitaciones apropiadas», que se reitera en la Resolución 428 del mismo día. En 1979 el Comité de Ministros invitó a incluir el derecho a buscar y recibir información pública.

$36 \mathrm{La}$ «búsqueda de una política de información abierta en el sector público, incluido el acceso a la información» forma parte de la Recomendación 19 (1981), de 25 de noviembre.

37 Aprobada por el Comité de Ministros el 21 de febrero 2002 en la reunión 784a de Delegados de los Ministros ) http://goo.gl/qUpRlf<

38 Comité de Ministros del Consejo Decisión No. CM/866/04052005 de 3-5 de mayo.

39 Abierto a la firma el 18 de junio de 2009 en Troms $\varnothing$, Noruega, firmado por 14 Estados miembros y ratificado por 7 a fecha junio 2015, siendo necesarias 10 ratificaciones para su entrada en vigor.

$40 \mathrm{Al}$ respecto, las Decisiones de la Comisión de 31 de mayo de 1974 sobre acceso por concejales a información); de 3 de octubre de 1979 (acceso por el interesado a documentos que le afectan; la de 14 de diciembre de 1979 sobre acceso a información sobre comisión de régimen penitenciario y la de 14 de octubre 
Hasta el 2009 hubo un rechazo a incluir el acceso a la información pública en el ámbito de la libertad de expresión del artículo $10 \mathrm{CEDH}^{41}$. Cuestión diferente es que en diversas ocasiones el acceso a la información pública del propio solicitante se garantizaba por el derecho de vida privada del artículo $8^{42}$ o en su caso del artículo $6 \mathrm{CEDH}$ sobre debido proceso ${ }^{43}$.

Los efectos del caso Claude Reyes y Otros v. Chile se percibieron ya en $2006^{44}$ y aunque de modo tímido en dos sentencias de casos de Hungría: la STEDH Társaság a Szabadságjogokért contra Hungría, de 14 de julio de $2009^{45}$ y la STEDH Kenedi v. Hungría, de 26 de agosto de 2009 (en especial, § 43), en las que se vinculó el acceso a la información pública con el artículo $10 \mathrm{CEDH}$. La STEDH Youth Initiative for Human Rights c. Serbia, de 25 de septiembre de 2013 sigue la misma línea y subraya que el acceso a la información pública es esencial para el control público por ONGs que hacen un papel similar a la prensa ( $\$ 20$ y 24). No obstante, aunque la conclusión es similar, en la STEDH Guseva v. Bulgaria de 17 de febrero de 2015, se afirma que no hay un derecho general de acceso a la información pública (\$ 36), sino más bien vinculado a sujetos cualificados como periodistas y defensores de los derechos humanos ( $\$ 37)$ o a una ONG «vinculada» a asuntos de interés público (§ 38).

\section{El test que elabora el TEDH en noviembre de 2016 para saber si el derecho de acceso a la información tiene o no la protección de derecho fundamental en cada caso concreto}

Resulta decisiva la ya mencionada STEHD Gran Sala, de 8 de noviembre de 2016 caso Magyar ${ }^{46}$. En la misma se aborda frontal y profundamente la cuestión de la naturaleza del derecho de acceso a la información.

de 1991, respecto del acceso por las esposas de presos políticos de ciudadanos europeos en un país africano a información sobre el paradero y estado de sus esposos.

41 Como se señaló en la STEDH Leander v. Suecia de 26 de marzo de 1987 y otras que la mencionan: «El art. 10 no confiere al individuo [...] un derecho de acceso a un registro que contenga información sobre su situación personal, ni conlleva la obligación del Gobierno de facilitar una información tal al individuo» (\$74).

42 Básicamente las STEDH Leander v. Suecia de 26 marzo de 1987; Gaskin v. Reino Unido, de 7 de julio de 1989 ; Guerra y otros v. Italia, de 19 de febrero de 1998; McGinley y Egan v. Reino Unido, de 9 de junio 1998; Odièvre v. Francia, de 13 febrero de 2003; Sîrbu y otros v. Moldova, de 15 junio de 2004; Roche v. Reino Unido, de 19 octubre de 2005 y Sdružení Jihočeské Matky v. la República Checa, de 10 de julio de 2006.

43 STEDH 2004 Loiusieu v. Francia, de 18 de noviembre de 2003

44 En la decisión de inadmisibilidad del caso Sdružení Jihočeské Matky v. la República Checa, de 10 de julio de 2006 se consideró «que la negación de la solicitud afectó el derecho de la actora de recibir la información».

45 En la que se reconoce que «la Corte recientemente ha avanzado hacia una interpretación más amplia de la noción de «libertad de recibir información» (\$35). Se entiende que la denegación de información es una barrera que se vincula a cierta «censura» (\$ 36) que "pueden desalentar a los que trabajan en los medios de comunicación o campos relacionados de perseguir estos asuntos» (\$38) impidiéndoles su posibilidad de ser «perros guardianes públicos» («public watchdogs»). Por ello considera la violación del art. $10 \mathrm{CEDH}$.

46 (§ 11-20) Magyar Helsinki Bizottság (Comité Helsinki de Hungría), es una ONG que supervisa la aplicación de las normas internacionales de derechos humanos en Hungría. Realizó una investigación sobre la 
El Tribunal afirma contundentemente que «el derecho a recibir la información no puede ser interpretado como que impone a un Estado obligaciones positivas de recopilar y difundir información de oficio [...] el artículo 10 no confiere a los particulares un derecho de acceso a la información en poder de una autoridad pública, ni obliga al Gobierno a dar dicha información a la persona» (§ 156).

Sin embargo, en el mismo párrafo afirma que «tal derecho u obligación puede surgir $[\ldots]$ en circunstancias en que el acceso a la información es fundamental para el ejercicio individual del derecho a la libertad de expresión, en particular, de «la libertad de recibir y difundir informaciones» [art. $10 \mathrm{CEDH}]$ y su negación constituye una interferencia con este derecho» (§ 156). Sobre esta base, el TEDH de modo sistemático (§ 158-169) elabora un test o escrutinio de cuatro elementos para aplicar en cada caso concreto. Son cuatro las preguntas que cabe contestar afirmativamente:

$1^{\circ}$ ¿Cuál es la finalidad de la solicitud de la información? (§ 158) Se precisa que se trate de «actividades periodísticas u otras actividades que creen un foro para el debate público o constituyan un elemento esencial para el dicho debate». Esto choca algo con que no sea necesario alegar finalidad alguna para ejercer el derecho de acceso. Ahora bien, habrá que motivar la petición si se quiere gozar de la iusfundamentalidad y, como viene ya viene sucediendo con la jurisprudencia del TJUE, resulta sumamente difícil que en una ponderación de derechos deba prevalecer el acceso a la información si no se conoce la finalidad y alcance de concretos de la información que se solicita para su vinculación con el interés público. Este primer requisito a mi juicio es inseparable del segundo elemento del test.

$2^{\circ}$ ¿La información solicitada es de interés público? (§ 160). La información solicitada debe «proporcionar transparencia sobre la forma de gestión de los asuntos públicos y en los asuntos de interés para la sociedad en su conjunto y por lo tanto permite la participación en la gestión pública por el público en general» (§ 161). En cada caso concreto debe analizarse si las informaciones solicitadas «afectan el bienestar de los ciudadanos o a la vida de la comunidad, a la controversia, problemas sociales». Se recuerda asimismo en la línea la STEDH Carolina de Mónaco v Alemania de 24 junio 2004, que el interés del público, la mera «sed de información», no es interés público (§ 162). La vinculación de la información solicitada con los derechos fundamentales facilita que se considere de interés público. En el caso concreto, la información solicitada estaba vinculada a la investigación sobre el sistema de defensa legal pública, «estrechamente relacionada con el derecho a un juicio justo [...] cualquier crítica o mejora sugerida respecto de un servicio tan directamente conectado al derecho a un juicio justo debe ser vista como un tema de interés público legítimo» (§ 197). El test del interés o relevancia pública no es en modo alguno nuevo en el ámbito de la libertad de expresión e información. Pese a la incertidumbre para cada

calidad de los abogados de oficio y para ello solicitó información y datos personales de abogados de oficio a comisarías de policía, dos de ellas se negaron a facilitarla por considerar que los abogados no realizan funciones estatales, municipales o públicas. Los tribunales húngaros ratificaron esta decisión. 
caso concreto, se trata de una valoración de naturaleza jurídica y existe nutrida jurisprudencia que es bien posible que haya que amoldar al ámbito concreto del acceso a la información pública. A mi juicio este análisis del interés público es inseparable al juicio de la finalidad del acceso a la infomación. La información solicitada por sí misma puede no dar pistas sobre su interés público si no va vinculada con la finalidad que se persigue. La clave en el futuro será la valoración del interés público en los supuestos en los que aunque el solicitante pida la información para satisfacer un interés privado, su acción contribuya sin duda al interés público. Se trata de habituales supuesto en que solicita la información quien no ha obtenido una subvención, un contrato, un empleo o beneficio público y quiere fiscalizar la actuación pública.

$3^{\circ}$ ¿Quién pide la información desarrolla efectivamente un papel de «perro guardian» de la democracia frente a los abusos del poder? El solicitante de información ha de ser cualificado. No se trata de algo novedoso pues el la argumentación de la importancia del papel de perro guardian atribuido incialmente a la prensa para reforzar su ejercicio de la libertad de expresión e información se ha aplicado en 158 sentencias sobre el artículo $10 \mathrm{CEDH}$, desde la STEDH caso Barthold vs Alemania de 25 de marzo de 1985 y el caso Lingens contra Austria de 8 de julio de 1986. Y la extensión de este carácter más allá de los periodistas también se detecta en los últimos años. Pues bien, para cumplir con este requisito, el solicitante de la información ha de tratarse de un «periodista» o «un organismo de control social o una ONG» (§165). En cualquier caso se insiste que la proección especial «no se limita a la prensa [...] también [...] entre otros, ONG» (\$166); la cualidad «se extiende también a los investigadores académicos $[\ldots]$ y autores de la literatura sobre asuntos de público $[\ldots$ y] dada la importancia del papel desempeñado por la Internet en la mejora del acceso del público a las noticias y facilitar la difusión de información, la función de los bloggers y usuarios populares de los «social media» también puede ser asimilada a la de «vigilantes públicos»» (\$168). A mi juicio este criterio será fácilmente desbordado en el futuro, puesto que si la finalidad del acceso es pública y se solicita información pública, será bien difícil restringir la protección especial sólo por la naturaleza del sujeto. En cualquier caso, si los solicitantes pertenecen a los colectivos mencionados habrá una presunción favorable a dotar de la protección iusfundamental.

$4^{\mathrm{o}}$ ¿La información solicitada ya está lista y disponible para facilitarse? (Ready and available information, §169-170). Se trata de que el poder público no tenga que reelaborar la información, esto es, que «no exige la recogida de datos por parte del Gobierno» sino sólo dar la que tenga. El TEDH recuerda que no considerar incumplido este requisito si las dificultades para dar la información se deben a las malas prácticas de la propia autoridad $(\$ 169)^{47}$.

Pues bien, a partir de este test, si la contestación es afirmativa en los cuatro elementos, el acceso a la información pública contará con la protección

47 Se cita en este sentido la STEDH de 28 de noviembre, caso Österreichische Vereinigung v. Austria. 
iusfundamental de la libertad de expresión e información. En el caso concreto el TEDH (§ 180) así lo considera y afirma que ha habido una interferencia o restricción del artículo $10 \mathrm{CEDH}$.

Obviamente todo derecho tiene límites y a partir de esta protección cualificada es cuando procede examinar si las restricciones pacticadas superan las exigencias para ser admisibles ( $\$ 181-200)$, esto es, analizar «si la injerencia estaba justificada» ( 181 y ss.), si contaba con un «fin legítimo» (\$186) y era «necesaria en una sociedad democrática» (§ 187). Y por cuanto al caso concreto, se concluye que las justificaciones del gobierno «no eran suficientes para demostrar que la interferencia se quejó era «necesaria en una sociedad democrática» $[\ldots .$.$] a pesar de margen de apre-$ ciación del Estado demandado, no había una relación razonable de proporcionalidad entre la medida de denuncia y la finalidad legítima perseguida» $(\$ 200)^{48}$.

Esta muy reciente sentencia asienta nuevas bases para abordar la protección fundamental o no del acceso a la información pública que habrán de tener su desarrollo y aplicación por el TEDH en el futuro y, sobre todo, interiorizarse y articulares con los sistemas nacionales. En cualquier caso, esta nueva jurisprudencia debe convivir con el hecho incontestable del reconocimiento del derecho de acceso a la información como derecho fundamental en la UE, que también se proyecta, aunque de forma limitada al ámbito interno español, como luego se expone.

\section{El reconocimiento de un derecho fundamental autónomo en la Unión Europea}

En la $\mathrm{UE}^{49}$, existen precedentes de resoluciones sobre el derecho de acceso a la información como derecho fundamental desde los años $80^{50}$. En todo caso, la preocupación en el tema se inició en 1992 por la presión inicial de los Países

48 Se afirma que «La denegación de la solicitud afectaba de manera efectiva a la contribución de la ONG solicitante a un debate público sobre una cuestión de interés general.» (\$197). «Aunque la solicitud de información ciertamente afecte a datos personales, no se trataba de información fuera del dominio público» (\$197).

49 En español destaca el exhaustivo estudio Guichot Reina E.: Transparencia y acceso a la información en el derecho europeo, cit. pp. 73-284. Más reciente, también AA.VV. Transparencia y acceso a la información pública, XIII Informe de la FIO, cit. pp. 90-99. Quien suscribe tiene diversos estudios sobre la materia incorporando la literatura internacional de referencia, si bien, en cualquier caso, cabe remitir a los muchos trabajos de Curtin (https://goo.gl/BhSxKz), entre otros, de acceso completo y más actuales, CurTiN, D.: «Judging EU Secrecy», Cabiers de Droit Européen 2012/2; Amsterdam Centre for European Law and Governance Research Paper No. 2012-07 http://dx.doi.org/10.2139/ssrn.2184249; Meijer, A., Curtin D. y Hillebrandt, M.: «Transparency in the Council of Ministers of the EU: An Institutional Approach», versión de octubre de 2012 de acceso completo del publicado en European Law Journal, Vol. 20, Issue 1, pp. 1-20, 2014 (https:// ssrn.com/abstract $=2166871$ ). De los mismos autores, «Open Government: Connecting Vision and Voice,» 78(1) Int Rev Adm Sci 10, 2012. Su último trabajo «Open Government in the European Union: A Moving Target», en Blockmans, S. y Lazowski A. (Eds.), Research Handbook on EU Institutional Law, Cheltenham, Edward Elgar Publishing, 2016.

50 Así, Resoluciones del Parlamento Europeo de 24 de mayo de 1984 y de 23 de enero de 1988 sobre la publicidad de los procedimientos comunitarios. Asimismo hubo algunas decisiones de abrir archivos históricos en 1983 . 
Bajos, reforzada con la entrada de Suecia, un país con larga tradición en transparencia, como lo acredita su Ley de acceso a la información de 1766. Desde el Tratado de Maastricht de 1992 se fue incorporando el derecho de acceso en los tratados e instrumentando las normas en las distintas instituciones y órganos ${ }^{51}$. En su versión dada por el Tratado de Ámsterdam de 1997 el artículo 255 del Tratado de la Comunidad Europea reconocía el derecho. No obstante, el Tribunal de Justicia recordaría la necesidad de la interposición legislativa para su aplicación. Con el Tratado de Lisboa de 2007 aquel artículo 255 pasó a ser (con alguna modificación) el artículo $15.3^{\circ}$ del TFUE. Se trataba de un derecho a la información en «cualquiera que sea su soporte», de cualquier residente y ante cualquier órgano o institución de la UE. Asímismo este artículo 15 TFUE vinculó la transparencia a la «buena gobernanza»y «principio de apertura» (ap. $1^{\circ}$ ) al tiempo de afirmar el carácter público de sesiones de Parlamento, así del Consejo (cuando delibere y vote sobre un proyecto de acto legislativo).

Siguiendo el mandato del artículo 255 del Tratado de la Comunidad Europea, se aprobó el Reglamento (CE) n 1049/2001 del Parlamento Europeo y del Consejo, de 30 de mayo de 2001, relativo al acceso del público a los documentos del Parlamento Europeo, del Consejo y de la Comisión. En el contexto de 2001 se trataba de una norma muy avanzada, máxime si se tiene en cuenta que era para una organización supranacional. Desde 2003, la Comisión publica un informe anual sobre la aplicación del reglamento. Y desde 2008 hay dos propuestas de la Comisión Europea, una de fondo ${ }^{52}$ y otra más técnica ${ }^{53}$, para la revisión del Reglamento 1049/2001. Tras la posición del Parlamento Europeo el 15 de diciembre 2011 y sus enmiendas, la reforma sigue siendo objeto de reflexión, por no decir que está en punto muerto.

Así pues, en la UE el reconocimiento del derecho de acceso a la información pública como derecho fundamental no viene de la mano de la libertad de expresión, sino como un derecho autónomo. Se trata del «Derecho de acceso a los documentos» reconocido en el artículo 42 Carta DFUE ${ }^{54}$ : «Todo ciudadano de la Unión o toda persona física o jurídica que resida o tenga su domicilio social en un Estado miembro tiene derecho a acceder a los documentos del Parlamento Europeo, del Consejo y de la Comisión.» ${ }^{55}$

51 A finales de 1997 catorce instituciones y órganos adoptaron o acordaron normas de acceso a la información.

52 La primera propuesta de refundición del Reglamento, presentada por la Comisión el 30 de abril de 2008, introduce una serie de modificaciones sustanciales, para clarificar la interpretación del Reglamento

53 Relativa al alcance a todas instituciones y órganos en razón del nuevo art. 15 del Tratado de Funcionamiento.

54 Además de la bibliografía ya mencionada, entre otros, acceso completo puede seguirse el GONZÁLEZ Alonso, L. N.: «Comentario al art. 42», Mangas Martín, A. (ed.): Carta de los derechos fundamentales de la Unión Europea: comentario art. por art., Fundación BBVA, Bilbao, 2009.

55 Se añadía que «Dado que este derecho es el reconocido en el art. 255 del TCCE, de conformidad con lo dispuesto en el apartado 2 del art. 52, se aplicará en las condiciones determinadas por el Tratado.» 
La Carta fue "proclamada solemnemente» en el Consejo Europeo de Niza en 2000. Su fuerza normativa se hizo esperar hasta la entrada en vigor en 2009 del Tratado de Lisboa de 2007.

\section{Un derecho fundamental para los tribunales de la UE, aunque hasta 2015 ni lo mencionaban}

La jurisprudencia de la $\mathrm{UE}^{56}$ ha tenido desde antiguo un importante papel en el desarrollo del derecho de acceso a la información pública. Se trata de una treintena de sentencias del Tribunal de Justicia (TJUE) y un centenar de sentencias del antiguo Tribunal de Primera Instancia, hoy Tribunal General (TGUE) ${ }^{57}$.

Periodistas, investigadores, parlamentarios y, sobre todo, empresas envueltas en procesos judiciales, sancionatorios o inmersas en regulación específica han sido los demandantes en la mayoría de los supuestos. En los últimos años cada vez más asociaciones y ONGs. En la mayoría de los casos todos ellos han resultado victoriosos frente a instituciones y órganos de la UE que han ido variando sus prácticas al ritmo de la jurisprudencia y de las acciones del Defensor del Pueblo europeo.

Ahora bien, los tribunales de la UE han huido de la polémica categorización del derecho de acceso a la información como derecho fundamental. Antes de estar el derecho de acceso reconocido en los tratados, los tribunales lo denominaban «principio», sin mayores precisiones ${ }^{58}$. En otras ocasiones se mencionaba la «afirmación progresiva del derecho de acceso ${ }^{59}$. Se señalaba que este derecho sólo tenía existencia en virtud de la normativa interna del Consejo y de la Comisión (WWF, Van der Val ${ }^{60}$. En 1995 el Abogado General Tesauro incitó al reconocimiento como derecho fundamental en sus conclusiones ${ }^{61}$. Y la sentencia del Tribunal de Primera Instancia del caso Hautala de 1999 habló del «principio del derecho a la

56 En los informes anuales de la aplicación del reglamento por la Comisión Europea hay un apartado que glosa todas las sentencias habidas ese año.

57101 sentencias del Tribunal General, La búsqueda en la base de datos arroja cientos de resultados bajo la categoría de «Acceso a los documentos».

58 Así en el caso Carvel de 1995 ( 65 y ss.) o en el caso Svenska, de 1998 se aludió al acceso a la información como «principio" sin mayores precisiones ( $\$ 62$ y ss.).

59 En la STJUE del caso Holanda Caso /Consejo de 1996, el Tribunal simplemente «tiene en cuenta» las importantes conclusiones del Abogado General Tesauro (\$ 34$)$ y señaló «una afirmación progresiva del derecho de acceso de los particulares a los documentos que obran en poder de las autoridades públicas» (§ 36). Esta simple tensión era la causante de que las instituciones adoptaran decisiones de carácter interno que podían producir efectos jurídicos a terceros ( $\$ 37$ y 38).

60 El Tribunal de Primera Instancia en las sentencias caso WWF UK (1997, § 55) y Van der Val (1998, $\S 41$ ), en coherencia con lo anterior, se considera el acceso a los documentos como derecho configurado por la Decisión interna del Consejo o de la Comisión, según se trate, sin referencia a su consideración como principio.

61 El Abogado General Tesauro en sus conclusiones del caso Holanda/Consejo de 1995, de 28 de noviembre de 1995 afirmó el carácter «derecho fundamental civil» de acceso a la información pública (§ 14 y $15)$, a la vez de ser «un principio de la acción de las instituciones» (§ 21). Bajo esta comprensión, las Decisiones internas que regulaban este derecho no lo creaban, pues era previo, sino que eran mera expresión del procedimiento a seguir al respecto $(\$ 21)$. 
información» ( $\$ 87)$, dando a entender que se le confería tratamiento de principio general del Derecho comunitario, situado al lado del de proporcionalidad. En las famosas conclusiones en el caso Hautala ${ }^{62}$ presentadas el 10 de julio de 2001 Philipe Légere insistió en la condición de derecho fundamental, principio general y tradición constitucional del derecho de acceso a la información, todo ello gracias a una profusa fundamentación del todo interesante para el reconocimiento de principios generales, tradiciones constitucionales y derechos fundamentales, así como relativa a la naturaleza jurídica de la CDFUE. Pese al tenor de sus conclusiones de 2001, un año después y en su actuación en el caso Interporc II $^{63}$, de 12 de marzo de 2002 el mismo Abogado General Léger se desdijo totalmente de sus afirmaciones anteriores, llegando a negar categóricamente que exista un derecho fundamental de acceso ( $\$ 78-80)$. En el caso Petrie de $2001^{64}$, el Tribunal de Primera Instancia negó la consideración de derecho con efecto directo y se afirmaba de forma inequívoca la necesidad de interposición legislativa respecto del derecho de acceso a los documentos reconocido en el artículo 255 del Tratado de las Comunidades.

Pese a no afirmarse como derecho fundamental, sin duda se lo ha tratado como tal, especialmente en los últimos años, al interpretar de forma muy restrictiva los límites del Reglamento 1049/2001. Es habitual la afirmación de que «el derecho de acceso del público a los documentos de las instituciones está ligado al carácter democrático de éstas», por lo que «las excepciones a este derecho enumeradas en su artículo 4 [del Reglamento] deben interpretarse y aplicarse en sentido estricto» (STJUE Suecia/Comisión, C 64/05 P, § 66) ${ }^{65}$.

Pese a las alegaciones de las partes, las sentencias no hacen especulaciones sobre la iusfundamentalidad del derecho de acceso, aunque que el artículo 42 de la CDFUE entró en vigor en 2009. No obstante, desde 2015, en algunos casos ya se menciona el artículo 42 de la Carta como Derecho aplicable por el TGUE, aunque sin extraer de ello consecuencia alguna. Así ha sido hasta la STJUE Comisión Europea / Patrick Breyer, C-213/15 P de 18 de julio de 2017. En la misma se afirma la «consagración del derecho de acceso a los documentos en al artículo 42» y por ello del «objetivo de una de administración europea abierta», como consecuencia se deriva la «interpretación amplia del principio de acceso a los documentos» $(\S 52)^{66}$.

62 TJUE, Caso Consejo / Hautala y otros, C-353/99 P sentencia de 6 de diciembre de 2001

63 TJUE, Caso Interporc II, C-41/00 P, sentencia del Tribunal de Justicia de 6 de marzo de 2003

64 David Petrie y otros contra la Comisión (T-191/99), sentencia del Tribunal de Primera Instancia, de 11 de diciembre de 2001.

65 Así, se «en relación con la regulación anterior al Reglamento n ${ }^{\circ} 1049 / 2001$, las sentencias de 11 de enero de 2000, Países Bajos y Van der Wal/Comisión, C174/98 P y C189/98 P, Rec. p. I1, apartado 27, y Consejo/Hautala, antes citada, apartados 24 y 25, así como, por lo que respecta al Reglamento n $1049 / 2001$, la sentencia de 1 de febrero de 2007, Sison/Consejo, C266/05 P, Rec. p. I1233, apartado 63).» A éstas cabe añadir, entre otras, la STG de 22 de marzo de 2011 asunto T233/09, caso Access Info Europe y la STJUE de 3 de julio de 2014, asunto C350/12 P caso Sophie in 't Veld.

66 Así, simplemente se menciona como Derecho aplicable en la STG de 25 de marzo de 2015 Sea Handling SpA contra Comisión Europea (aps. 50 y 107) y en la STG de 4 de junio de 2015 Versorgungswerk der Zahnärztekammer Schleswig-Holstein contra Banco Central Europeo (ap. 105). Y con referencia al 


\section{La proyección en España del derecho fundamental de acceso a los documentos}

El objeto de este estudio excede la proyección interna en España del derecho de derecho de acceso reconocido internacionalmente, si bien, cabe hacer algunas precisiones básicas. La proyección del artículo 42 CDFUE puede apuntalar y fortalecer la fundamentalidad del derecho de acceso a la información en España.

En primer término, el derecho de acceso reconocido por la CDFUE va más allá de la propia UE. En en razón del artículo $51.1^{\circ}$ de la Carta, este derecho del artículo 42 se reconoce ante las instituciones y órganos de la Unión. Ahora bien, los Estados miembros están vinculados por dicho derecho «únicamente cuando apliquen el Derecho de la Unión». En consecuencia, las solicitudes de información frente a poderes públicos españoles con relación a la aplicación por éstas de Derecho de la UE habrá que someterlas al régimen y protección de derecho fundamental. Lo mismo sucederá respecto de los accesos a la información regulados por normativa europea directamente o en transposición de la misma, como pueda ser el caso del medio ambiente ${ }^{67}$. Las posibilidades no son en modo alguno escasas.

Pero es más, se puede sostener que el alcance en España como derecho fundamental debe generalizarse merced a la expansión del Derecho de la UE en los Estados miembros. El alcance de la CDFUE en el Derecho interno y sus relaciones con el Derecho de la Unión es una cuestión abierta y compleja ${ }^{68}$. A este respecto, bajo una visión claramente expansiva puede recordarse que el TJUE ha llegado a señalar que puede bastar con que los Estados miembros persigan un objetivo establecido en los Tratados de la UE o en el Derecho derivado de la Unión para que la Carta deba aplicarse en el Estado miembro ${ }^{69}$. Y la democracia y la transparencia fácilmente pueden calificarse como objetivos de la UE.

En segundo término, el derecho de acceso a la información pública reconocido como derecho fundamental en la UE goza de un nivel de protección más amplio que en el marco del CEDH. En este punto cabe recordar que el artículo 52.3 CDFUE dispone que la UE puede conferir una «protección más extensa» que la del CEDH. Por ello, para gozar de la protección iusfundamental del artículo 42 DFUE en España no sería imprescindible contar con los requisitos que impone el TEDH desde noviembre de 2016 para considerar la conexión con la libertad de expresión e información (no se exigirá necesariamente finalidad de interés público, sujetos cualificados, que la información solicitada sea de interés público, etc.).

«derecho fundamental», la STG de 15 de julio de 2015, Gert-Jan Dennekamp contra Parlamento Europeo (ap. 60).

67 Así sucede con la Ley 27/2006, de 18 de julio, que incorpora las Directivas 2003/4/CE y 2003/35/CE.

68 En español, por todos cabe seguir MARTÍNEZ-VARES GARCÍA, S. DE LA QUADRA-SALCEDO, T., «La tutela multinivel de los derechos fundamentales», ponencia española en XVI Reunión trilateral de los Tribunales Constitucionales de Italia, Portugal y España, Santiago de Compostela, octubre de 2014.

69 Así, en la STJUE (Gran Sala) de 26 de febrero de 2013, Asunto C-617/10, caso Åklagaren contra Hans Åkerberg Fransson (Suecia). 
Además, y a mayor abundancia, en nuestro país el artículo 2 de la Ley Orgánica $1 / 2008$, de 30 de julio prescribe que «las normas relativas a los derechos fundamentales y a las libertades que la Constitución reconoce se interpretarán también de conformidad con lo dispuesto en la Carta de los Derechos Fundamentales». Pese a que pueda dudarse del acierto y alcance de este precepto en razón del artículo $10.2^{\circ} \mathrm{CE}$, este precepto puede sumarse a otros por los que interpretar las normas relativas al derecho de acceso en España de conformidad con la fundamentalidad del artículo 42 de la CDFUE.

\section{LOS TITULARES, LOS SUJETOS OBLIGADOS Y LA INFORMACIÓN OBJETO DEL DERECHO}

\section{El titular del derecho y la protección iusfundamental más intensa en razón del ejercicio por sujetos cualificados}

Las «normas de la ONU» del $2000^{70}$ hacen referencia a que el derecho de acceso a la información pública es un derecho de «todo miembro del público», sin mayor concreción. Sin embargo, en el ámbito de la ONU el derecho de acceso a la información se reconoce en el marco de la libertad de buscar información, reconocida inicialmente a los periodistas ${ }^{71}$. Como consecuencia, la Observación general $n^{0} 34$ del CDH de 2011 afirma que el acceso a la información pública es de los medios de comunicación para que faciliten al público los resultados de su actividad $(\S 18)^{72}$. No obstante, se extiende el derecho a otros sujetos que tienen especial vinculación con el control y vigilancia del poder público, como los autores en internet $(\S 44)^{73}$ o asociaciones

70 Así, simplemente se menciona como Derecho aplicable en la STG de 25 de marzo de 2015 Sea Handling SpA contra Comisión Europea (aps. 50 y 107) y en la STG de 4 de junio de 2015 Versorgungswerk der Zahnärztekammer Schleswig-Holstein contra Banco Central Europeo (ap. 105).

Así sucede con la Ley 27/2006, de 18 de julio, por la que se regulan los derechos de acceso a la información, de participación pública y de acceso a la justicia en materia de medio ambiente y se

Así, en la STJUE (Gran Sala) de 26 de febrero de 2013, Asunto C-617/10, caso Åklagaren contra Hans Åkerberg Fransson (Suecia).

Dentro del «Principio 4» del Informe del Relator Especial, Promoción y protección del derecho a libertad de opinión y expresión, ONU Doc. E/CN.4/2000/63, 18 enero 2000, pp. 30 y ss., cit.

71 Así en la Comunicación No 633/1995, Gauthier c. el Canadá, dictamen aprobado el 7 de abril de $1999(\$ 13.4)$

72 El «derecho de acceso a la información, interpretado junto con el art. 25 del Pacto, incluye el derecho que permite a los medios de comunicación tener acceso a la información sobre los asuntos públicos y el derecho del público en general a que los medios de comunicación le proporcionen los resultados de su actividad.» Y remite a la comunicación No 1334/2004, Mavlonov y Sa'di c. Uzbekistán.

73 La misma Observación general no 34 del CDH de 2011, aunque no directamente referida al acceso a la información pública, señala que «en la función periodística participan una amplia variedad de personas», entre ellos, «autores de blogs y otros que publican por su propia cuenta en medios de prensa, en Internet o por otros medios» $(\$ 44)$. 
defensoras de derechos humanos, como en el Dictamen CDN del caso Nurbek Toktakunov vs. Kirguistán (en especial $§ 6.3$ y $§ 7)^{74}$.

Este fenómeno se ha ido apreciando con mayor intensidad en el TEDH hasta su culminación con la STEHD de 8 de noviembre de 2016 caso Magyar. Según se ha expuesto infra, la naturaleza del solicitante ya forma parte del test para considerar que se trata de un derecho fundamental (§ 168). Aunque se reconoce el derecho de acceso no sólo a periodistas, pero sí que es importante que se trate de «perros guardianes públicos» («public watchdogs») que ejercen el control democrático. Así sucede con asociaciones defensoras de derechos (STEDH Társaság 14 de julio de 2009), historiadores en ámbitos sensibles (STEDH Youth Initiative de 25 de septiembre de 2013) u ONGs vinculadas a asuntos de interés público (STEDH Guseva v. Bulgaria de 17 de febrero de 2015). La clave va a resultar la extensión y generalización de estos sujetos en razón especialmente de internet y, si se me permite, la tendencia necesariamente será la generalización del derecho fundamental a todo sujeto que solicite información para finalidades de relevancia pública.

La situación es diferente en el caso de la UE, donde el derecho de acceso a la información tiene un reconocimiento desvinculado de la libertad de expresión pero en cualquier caso como derecho fundamental. Desde 1997 el derecho expresamente se reconoce a «todo ciudadano de la Unión, así como toda persona física o jurídica que resida o tenga su domicilio social en un Estado miembro» ${ }^{75}$. Es más, el artículo 2. $2^{\circ}$ del Reglamento n ${ }^{\circ}$ 1049/2001 permite reconocer el derecho incluso a cualquier persona y fuera del territorio de la UE.

La cualificación del acceso a la información en razón del sujeto tiene trascendencia interna para España respecto del ejercicio en el ámbito natural de su actividad por parlamentarios ${ }^{76}$ o concejales ${ }^{77}$ (artículo $23 \mathrm{CE}$ ) o por por sindicalistas

74 En la resolución se parte de la especial protección de acceso a la información para periodistas. No obstante, en este caso el solicitante era cualificado pues «es consultor jurídico de una asociación pública de derechos humanos y como tal se puede considerar que tiene funciones especiales de «vigilancia» sobre cuestiones de interés público.» Comunicación N $\mathrm{N}^{\circ}$ 1470/2006, 28 de marzo de 2011.

75 Así en el art. 255 del Tratado de las Comunidades en su versión de 1997, así como los actuales art. 15 TFUE y el art. 42 de la CDFUE. En este último caso, no tiene relevancia alguna que este derecho se ubique en el marco de los derechos de la ciudadanía europea.

76 Recientemente destaca la STS de 28 de septiembre de 2012 de la Sala Tercera que considera que el acceso a la información de los parlamentarios forma parte del contenido del art. 23 CE y son los reglamentos parlamentarios los que deben dotarle de la oportuna configuración legal con las necesarias garantías $\left(\mathrm{FJ} 3^{\circ}\right.$ ). Una descripción del régimen de acceso, aunque sin plantearse la aplicabilidad de la ley de transparencia, Santiago González Fernández: «El derecho de acceso a la información de los diputados en el marco de la transparencia», en VII Congreso Internacional en Gobierno, Administración y Políticas Públicas. GIGAPP 03-05 octubre 2016, acceso completo en internet.

$77 \mathrm{Al}$ respecto del derecho de acceso de los concejales, cabe tener en cuenta el art. 77 de la LRBRL y los arts. 14, 15 y 16 del Real Decreto 2568/85 (ROF). Éste sería el régimen especial a aplicar, así como concreciones que se dan en algunas normas autonómicas o desarrollos locales (por ejemplo: art. 128 Ley 6/2010 de la Generalitat, de Régimen Local de la Comunitat Valenciana). Por cuanto a la aplicabilidad de la Ley 19/2013 y su régimen de garantías, la más completa y reciente aproximación la acaba de publicar BLANES 
(art. $28 \mathrm{CE})^{78}$. En estos supuestos, sin duda, la protección, garantías y balance ante otros derechos o intereses han de ser más intensas, las propias de un derecho fundamental, tal y como sucede en el caso de la libertad de expresión e información a juicio del TEDH. En modo alguno puede admitirse que el acceso a la información pública por sujetos cualificados cuente con una protección y garantías menores a que si se tratara del acceso por cualquier ciudadano en razón de la protección legal de la Ley 19/2013 estatal y sus secuelas autonómicas. Lamentablemente, hay importantes discrepancias entre las distintas autoridades de transparencia en España al respecto de la aplicabilidad de la Ley 19/2013 en estos supuestos y la competencia de las propias autoridades en estos casos.

Pues bien, recientemente el Consejo de transparencia valenciano en su resolución de 3 de abril de 2017 (exp. 21/2016) ${ }^{79}$ ha considerado que el régimen especial de protección que implica la concurrencia de un derecho fundamental con la Ley 19/2013 debe articularse a través de la Disposición adicional primera. En consecuencia, la protección iusfundamental más intensa del acceso a la información debe considerarse como régimen «específico» y el régimen de la Ley 19/2013 se aplicará supletoriamente ${ }^{80}$. Esto mismo debe de predicarse en supuestos en los que el acceso a la información pública se vincula a otros derechos fundamentales como, por ejemplo, el acceso a datos propios del solicitante y el derecho de protección de datos (art. 18.4 CE) o la solicitud de información para poder acceder a la justicia (art. $24 \mathrm{CE}$ ).

\section{Los sujetos obligados a dar información}

Internacionalmente es amplio en concepto de quiénes son los sujetos obligados por el derecho de acceso a la información, si bien con particularidades especialmente con el poder legislativo y ejecutivo. Los influyentes Principios de 1999 de la organización «Artículo 19» ya incluyeron como obligado a todo poder público (incluidos legislativo o judicial, principio $\left.\mathrm{n}^{\circ} 4\right)$. Ello se ratifica en la Observación general $\mathrm{n}^{\circ} 34$ de 2011 del CDH (\$ 18).

En el marco del CdE, la Recomendación de 21 de febrero de 2002 del Comité de Ministros del CdE tenía una visión amplia de las autoridades públicas

Miguel Á.: «Los concejales pueden presentar la reclamación prevista en las leyes de transparencia» https:// miguelangelblanes.com/tag/concejales/

78 Así, por ejemplo, en el ámbito laboral, se regula el acceso de información del comité de empresa en el art. 64 del Estatuto de los Trabajadores. En sentido muy similar, cabe tener en cuenta el art. 10.3 Ley Orgánica 11/1985 de Libertad Sindical respecto de delegados sindicales y comité de empresa. Para el ámbito de la función pública cabe tener en cuenta los arts. 40 y 41 Estatuto Básico del Empleado Público. Al respecto del acceso a la información sindical, entre otras, SSTC 94/1995 y 168/1996).

79 Cuyo ponente es quien suscribe, accesible en www.conselltransparencia.gva.es

80 El tema excede ahora su análisis exhaustivo. En general sobre el régimen jurídico aplicable en razón de esta Disposición adicional, hay que tener en cuenta el Criterio Interpretativo 8/2015 de fecha 12 de noviembre de 2015 del consejo estatal. Si bien tanto doctrinalmente como otras autoridades mantienen criterios sensiblemente diferentes al del Consejo estatal. 
obligadas en sus definiciones; aunque se dejaba al ámbito nacional lo relativo al ejecutivo y legislativo (I y II. 1). Y así se vino a recoger en el Convenio no 205 del CdE de 2008, siendo obligados las autoridades públicas cuando ejerzan una «autoridad administrativa», «desarrollen funciones públicas» u «operen con fondos públicos, permitiendo particularidades para legislativo, judicial y privados (art. 1.2.a).

En el ámbito de la UE la normativa fue extendiendo el derecho más allá de las instituciones a los distintos órganos, especialmente con el artículo $15.3^{\circ}$ del TFUE. No obstante, hay previsiones especiales para el ámbito judicial, parlamentario y de algunos órganos específicos. En otra perspectiva, desde los inicios el acceso a la información se proyectó para los antiguos segundo y tercer pilares de la UE (política exterior y de seguridad y justicia e interior, por ejemplo, casos Svenska, Hautala, y Mattila) ${ }^{81}$.

Otro ámbito polémico es el alcance respecto de los sujetos privados. Al respecto, en las «Definiciones» de los Principios de 1999 de la ONG «Artículo 19» se afirmó que la consideración como sujeto obligado «se basará en el tipo de servicio prestado más que en designaciones formales», de modo que se incluyen entidades privadas que manejen información de «interés público fundamental, como el medio ambiente o la salud». El Convenio de Aarhus de $1998^{82}$ para el medio ambiente considera obligado a «Cualquier otra persona natural o jurídica que tenga responsabilidades o funciones públicas o que preste servicios públicos» (art. $2.2^{\circ}$ ). Y la Observación general $n^{\circ} 34$ del CDH de Naciones Unidas viene a extender al acceso a la información la doctrina de la posible responsabilidad del Estado por vulneraciones de la libertad de información respecto de entidades privadas ( $§$ 7) ${ }^{83}$. En el ámbito de la UE, la «regla del autor» permitía excluir el acceso a documentos que procedían de terceros y fue interpretándose restrictivamente por los Tribunales hasta que fue abolida con el Reglamento (CE) n 1049/2001.

\section{Un concepto amplio de información pública, no restringida al acceso al documento. Acceso parcial y no necesidad de reelaboración}

También se ha consolidado en el ámbito internacional que el objeto de la información a la que el ciudadano tiene derecho a acceder es muy amplio. La

81 Así, por ejemplo, en la STJUE caso Consejo / Hautala y otros, C-353/99 P sentencia de 6 de diciembre de 2001 y en el TPI, caso Svenska Journalistförbundet/Consejo de la Unión (T-174/95), Tribunal de Primera Instancia, de 17 de junio de 1998 o en el caso Mattila/Consejo y Comisión, (T-204/99), sentencia de 12 de junio de 2001

82 En el marco de la ONU, la Convención sobre el acceso a la información, la participación pública en la toma de decisiones y el acceso a la justicia en los asuntos ambientales fue adoptada en la Conferencia Ministerial «Medio Ambiente para Europa» celebrada en Aarhus, Dinamarca, el 25 de junio de 1998. Entró en vigor el 30 de octubre de 2001. Ha sido firmado por 47 estados y la UE, todos de Europa y Asia Central.

83 La OG No 34 remite a la Observación general No 31, párr. 8; véase la comunicación No 633/1995, Gauthier c. el Canadá, dictamen aprobado el 7 de abril de 1999. 
Convención de Aarhus de 1998 define la información muy ampliamente, para incluir «cualquier información en forma escrita, visual, auditiva, electrónica o en cualquier otra forma material», aunque su alcance, de conformidad con su propósito, está limitado a la información ambiental (art. 2. 3). Las definiciones de los Principios de la ONG «Artículo 19» abogan por un concepto amplio de información en cualquier soporte e incluyendo la información secreta. En esta línea, las llamadas «normas de la ONU» de 2000 ( $\$ 18)$ ya manejaron un concepto bien amplio de información, la «registrada en archivos públicos o procesada por el Estado» ${ }^{84}$.

El Comité de Derechos Humanos de la ONU en su Observación general n ${ }^{\circ}$ 34 de 2011 afirma que: «Esta información comprende los registros de que disponga el organismo público, independientemente de la forma en que esté almacenada la información, su fuente y la fecha de producción» (\$18). Este criterio se ha aplicado de modo concreto en su Dictamen CDN del caso Rafael Rodríguez Castañeda vs. México ( $\$ 7)$, considerando el acceso a papeletas de una votación como acceso a la información pública ${ }^{85}$. Además, en el Dictamen CDN del caso Nurbek Toktakunov vs. Kirguistán ${ }^{86}$ el contenido de la información —sobre penas de muerte - cualifica el acceso a la información pública solicitado.

En Europa la Recomendación de 21 de febrero de 2002 definió muy ampliamente los «documentos oficiales» (I), lo cual se siguió en el Convenio $\mathrm{n}^{\circ} 205$ del CdE de 2008 art. 1. 2. b) ${ }^{87}$. La UE ha seguido el camino de reconocer el acceso a «documentos» (art. 42 CDFUE, 15. $3^{\circ}$ TFUE, art. 3. a) Reglamento n ${ }^{\circ}$ 1049/2001). No obstante, la jurisprudencia primero y la normativa después flexibilizó el concepto para permitir el acceso — parcial en su caso — a toda la información en poder de la $\mathrm{UE}^{88}$. Se reconoce un derecho de veto de los Estados para que no se hagan públicos los documentos en poder de las instituciones de los que ellos son autores ${ }^{89}$. No obstante, los tribunales son bastante restrictivos al respecto en los casos de documentación interna y preparatoria, propia de los procesos decisionales.

84 Se trata del «Principio 4» del Informe del Relator Especial, Promoción y protección del derecho a libertad de opinión y expresión, ONU Doc. E/CN.4/2000/63, 18 enero 2000, pp. 30 y ss., cit.

85 Comunicación 2202/2012, CDN, caso Rafael Rodríguez Castañeda vs. México, de 18 de julio de 2013.

86 Comunicación $\mathrm{N}^{\circ}$ 1470/2006, 28 de marzo de 2011.

87 b) «documentos públicos» significa toda la información registrada [archivada] de cualquier forma, elaborada o recibida, y en posesión de las autoridades públicas.

$88 \mathrm{El}$ art. $15.3^{\circ}$ del Tratado de Funcionamiento expresó que se «tendrá derecho a acceder a los documentos de las instituciones, órganos y organismos de la Unión, cualquiera que sea su soporte». El Reglamento $\mathrm{n}^{\circ} 1049 / 2001$ de la UE reconoce el derecho de acceso «a todos los documentos que obren en poder de una institución; es decir, los documentos por ella elaborados o recibidos y que estén en su posesión, en todos los ámbitos de actividad de la UE.» (art. 3 a).

89 Así, el art. 4.5 dispone que «Un Estado miembro podrá solicitar a una institución que no divulgue sin su consentimiento previo un documento originario de dicho Estado». Ello es así de conformidad a la Declaración no 35 aneja al Acta final del Tratado de Ámsterdam que prevé que un Estado miembro podrá solicitar a la Comisión o al Consejo que no comunique a terceros un documento originario de dicho Estado sin su consentimiento previo. 
Cabe señalar que el derecho de acceso lo es a la información, por lo que en razón del principio de proporcionalidad debe reconocerse el acceso parcial a la información contenida en un documento si concurre alguna excepción o restricción, salvo que pierda sentido la información a la que se accede. Especialmente en Europa se ha recogido el acceso parcial. A este respecto, cabe seguir la Recomendación de 21 de febrero de 2002 del Comité de Ministros del CdE que contempla el acceso parcial (VII. 2) ${ }^{90}$, al igual que el Convenio n ${ }^{\circ} 205$ del CdE de 2008 (art. 6. $\left.2^{\circ}\right)^{91}$. En el caso de la UE, el acceso parcial fue resultado de una interpretación jurisprudencial: «el principio de proporcionalidad obliga asimismo al Consejo a considerar el acceso parcial a un documento» ${ }^{92}$. El acceso parcial pasó luego al artículo 4. $6^{\circ}$ del Reglamento 1049/2001. La Ley Modelo de la OEA es su artículo 42 también recoge la «divulgación parcial».

Otra pauta de interpretación importante la acaba de brindar la STEDH de 8 de noviembre de 2016 caso Magyar por cuanto el objeto del acceso a la información se limita a si la información solicitada que está lista y disponible para facilitarse (\$169-170) sin necesaria actividad o reelaboración. No obstante, también debe facilitarse la información aunque sea necesaria una actividad o reelaboración si es por causa de malas prácticas de la propia autoridad $(\$ 169)^{93}$.

\section{EL PRINCIPIO DE MÁXIMA TRANSPARENCIA, EL CONTENIDO DEL DERECHO DE ACCESO A LA INFORMACIÓN Y LAS OBLIGACIONES QUE COMPORTA}

\section{Principio de transparencia por defecto y máxima transparencia}

El principio de máxima transparencia o divulgación es un elemento integrante del derecho fundamental de acceso a la información del cuan dimanan diversos contenidos sustanciales. En razón del principio de máxima transparencia, no es preciso interés legítimo para el acceso; los límites o excepciones han de

90 «2. Si una limitación se aplica a parte de la información en un documento oficial, la autoridad pública, sin embargo, debe conceder acceso al resto de la información que contiene. Cualquier omisión deben indicarse claramente. Sin embargo, si la versión parcial del documento es engañosa o carente de sentido, dicho acceso puede ser denegado.»

91 «Art. 6 - Formas de acceder a los documentos públicos [... 2) Si una limitación se aplica a parte de la información de un documento oficial, la autoridad pública debe, sin embargo, conceder el acceso al resto de la información que contiene [el documento oficial]. Cualquier omisión debe ser indicada claramente. Sin embargo, si la versión parcial del documento es engañosa o carece de sentido, o si supone una carga manifiestamente irrazonable que la autoridad entregue el resto del documento, tal acceso puede ser rechazado.»

$92 \mathrm{Al}$ respecto, entre otras, ver las sentencias del caso Consejo / Hautala y otros, C-353/99 P sentencia de 6 de diciembre de 2001 ( $\$ 21$ y ss.). Cabe remitir también a los citados casos Kuijer, JT y Mattila.

93 Se cita en este sentido la STEDH de 28 de noviembre, caso Österreichische Vereinigung v. Austria 
ser las mínimas, imponiendo además la necesidad de motivar y probar las causas de la restricción. Asimismo, por defecto y ante la duda, debe facilitarse la información. De igual modo, de este principio fundamental deriva la obligación de publicidad activa. Y obviamente este principio es un potencial hermenéutico que despliega los efectos en todo ámbito posible en la interpretación de este nuevo derecho. Así pues y por lo expuesto, la importancia del principio de máxima transparencia es máxima, si se me permite; especialmente en países como España en los que está pendiente toda una reiterpretación de la legislación de transparencia de modo acorde a este principio. De ahí la centralidad de subrayar su fundamentación internacional.

Aunque con antecedentes en la UE desde 1993, este principio toma especialmente forma como Principio I de «Máxima divulgación» de los Principios de 1999 de la ONG «Artículo 19», «se presume que toda la información en poder de un órgano público deberá poder ser difundida» y se liga íntimamente a la naturaleza fundamental del derecho de acceso. «El principal objetivo de la legislación debe ser el de llevar a la práctica el principio de máxima divulgación.» Este principio se expresa directamente en la Declaración de los relatores de 200494: «derecho humano fundamental [...] en base al principio de transparencia máxima, estableciendo la suposición de que toda información está accesible, con sujeción apenas a un sistema escueto de excepciones.»

En la UE desde la Decisión del Consejo Europeo de Copenhague, el 22 de junio de 1993 se afirma en los el «principio de que los ciudadanos tengan el acceso más completo posible a la información» ${ }^{95}$. Este principio quedó en buena medida recogido en el Reglamento $n^{\circ} 1049 / 2001$ (art. 1 a) y referido por la jurisprudencia desde $2001^{96}$. El principio de máxima transparencia se integra en el derecho de acceso a la información. Así, en 2005 la jurisprudencia afirmó el «derecho de los ciudadanos de la UE a un acceso lo más amplio posible a los documentos» ${ }^{97}$. Este «acceso más completo posible» se ha ido consolidando más si cabe después ${ }^{98}$, incluso como «principio general» ${ }^{99}$, que «implica el derecho de

94 Declaración Conjunta, cit. El TJUE ya ha subrayado que no hay obligación de crear documentos que no existen (STUE Strack/Comisión, C-127/13 P, de 2 de octubre de 2014EU, § 38 y 46). Y recientemente se proyecta este criterio sobre la «facilidad» de operaciones y tratamientos «corrientes» respecto del acceso a la información en bases de datos (STJUE C 491/15 P, Rainer Typke/Comisión de 11 de enero de $2017, \S 33-43)$.

95 Bol. CE 6-1993, p. 16, apartado I.22.

96 STJUE caso Consejo / Hautala y otros, C-353/99 P de 6 de diciembre de 2001

97 Así la STPI (Tribunal de Primera Instancia), caso T-187/03, Scippacercola/Comisión, de 17 de marzo, ap. 29

98 Así, en sentencias de 18 de diciembre de 2007, Suecia/Comisión, C64/05 P, Rec, EU:C:2007:802, apartado 66; de 1 de julio de 2008, Suecia y Turco/Consejo, C39/05 P y C52/05 P, Rec, EU:C:2008:374, apartado 36, y de 6 de julio de 2006, Franchet y Byk/Comisión, T391/03 y T70/04, Rec, EU:T:2006:190, apartado 84).

99 Así, por ejemplo en la STGUE Technion y Technion Research \& Development Foundation/Comisión, caso T-480/11 apartado 43 . 
éste a que se divulgue todo el contenido de los documentos solicitados, derecho que sólo puede limitarse por la aplicación estricta de las excepciones previstas» ${ }^{100}$. La reciente STJUE C-213/15 P de 18 de julio de 2017 (§ 52) reafirma la máxima transparencia y la justifica en el reconocimiento como derecho fundamental por el artículo 42 CDFUE.

En América Latina y con claridad la SCIDH Claude Reyes de 2006 incorporó el «principio de máxima divulgación» en el contenido del derecho fundamental (§ 92).

\section{El derecho tiene como corolario diversas obligaciones para el Estado, entre ellas, la adecuación normativa}

El reconocimiento del derecho fundamental de acceso comporta una serie de obligaciones generales para el Estado. En las «normas de la $\mathrm{ONU}$ » $\left(\mathrm{n}^{\circ} 4\right)$ se afirma la obligación de garantía ${ }^{101}$, de lo que deriva «una posición servicial de la Administración, aportando aquella documentación que hubiera sido previa, correcta y claramente solicitada, en la medida en que no se encuentre temporalmente excluida del ejercicio del derecho.» (§ 18). En la SCIDH Claude Reyes de 2006 se afirma que el derecho a la información comporta «la obligación positiva del Estado de proporcionarla en tal forma que la persona pueda tener acceso para conocer la información o recibir una respuesta motivada cuando, por alguna razón reconocida por la Convención» (§ 77). ${ }^{102}$ En la misma dirección, en el Dictamen CDN del caso Nurbek Toktakunov vs. Kirguistán de $2011^{103}$ se afirma que del derecho deriva la obligación de que «la persona interesada tenga acceso a ella [la información] o reciba una respuesta que incluya una justificación» cuando concurra una restricción» (§ 7). La Observación general n ${ }^{\circ} 34$ del CDH de 2011 señala que «los Estados partes deberían poner en aplicación los procedimientos necesarios para tener acceso a la información, por ejemplo leyes sobre la libertad de información ${ }^{104}$. (§ 19). Destaca la SCIDH Claude Reyes de 2006 por cuanto el derecho fundamental de acceso comporta como contenido la obligación de adecuación normativa:

«Las acciones normativas son necesarias para garantizar el derecho: la supresión de normas y prácticas que entrañen violaciones a tales derechos, así como la

100 STGUE del caso Info Europe/Consejo, T-233/09, 22 de marzo de 2011 (§ 56).

101 Dentro del «Principio 4» del Informe del Relator Especial, Promoción y protección del derecho a libertad de opinión y expresión, ONU Doc. E/CN.4/2000/63, 18 enero 2000, pp. 30 y ss., cit. «4. El acceso a la información en poder del Estado es un derecho fundamental de los individuos. Los Estados están obligados a garantizar el ejercicio de este derecho.»

102 Y la sentencia del caso Gomes Lund y otros vs. Brasil de 24 de noviembre de 2010 afirma también «el derecho de las personas a recibir dicha información y la obligación positiva del Estado de suministrarla» (§ 197).

103 Comunicación No 1470/2006, 28 de marzo de 2011.

104 Observaciones finales sobre Azerbaiyán (CCPR/C/79/Add.38 (1994)). 
expedición de normas y el desarrollo de prácticas conducentes a la efectiva observancia de dichas garantías y cumplir con los parámetros convencionales y sólo pueden realizarse restricciones por las razones permitidas por la Convención» ( $\$ 101)$.

\section{La obligación de publicidad activa como integrante del derecho}

En el ámbito supranacional, las referencias a la publicidad activa son bastante escasas y discretas, especialmente en comparación con la cada vez más avanzada legislación de muchos países que incluye muchas obligaciones de difusión de información en webs y portales de transparencia. Sin perjuicio de ello, sí que se deriva que las obligaciones de publicidad activa son un medio para hacer efectivo el derecho y se integran en las obligaciones estatales, que son contenido del derecho subjetivo. Como he sostenido en otros lugares ${ }^{105}$, en buena medida la transparencia activa es la dimensión objetiva del derecho que adopta formas y obligaciones concretas en la normativa que lo desarrolla.

El Principio 2 de la ONG «Artículo 19» afirma la «obligación de publicar la información importante» $\mathrm{y}$ «La ley deberá establecer una obligación general de publicar y las categorías de información fundamentales.» Esta obligación general también se incorpora en las «normas de la ONU» de $2000^{106}$. Más discretas son aún las referencia a la publicidad activa en la Recomendación de 2002 y el Convenio 205 del Consejo de Europa de 2008 ${ }^{107}$. La Observación general $\mathrm{n}^{\circ} 34$ del $\mathrm{CDH}$ de 2011 afirma la publicidad activa «Para dar efecto al derecho de acceso a la información» y además señala que ha de haber un «acceso fácil, rápido, efectivo y práctico a esa información.» (§ 19).

\section{Obligación de promoción de la cultura de transparencia y gobierno abierto frente al secretismo, políticas de gobierno abierto}

La obligación de políticas de cultura de transparencia y gobierno abierto se ha integrado en el contenido del derecho de acceso a la información. El principio 3 de la ONG «Artículo 19» sobre «Promoción de la transparencia en la administración pública» subraya la necesidad de promover «una cultura de transparencia

105 «El derecho fundamental de acceso a la información, la transparencia de los poderes públicos y el Gobierno Abierto. Retos y oportunidades», en FernÁndez SAlmerón, M. y VAlero Torrijos, J. (coords.): Régimen jurídico de la transparencia en el sector público: acceso, uso y reutilización de la información administrativa, Thomson-Aranzadi, Madrid, 2014, pp. 37-71, en concreto pp. 54-55.

106 Dentro del «Principio 4» del Informe del Relator Especial, Promoción y protección del derecho a libertad de opinión y expresión, ONU Doc. E/CN.4/2000/63, 18 enero 2000, pp. 30 y ss., cit.

107 La Recomendación de 21 de febrero de 2002 del Comité de Ministros del CdE hace una escasa referencia a la información «hecha pública por iniciativa de las autoridades públicas» (XI) y el Convenio $n^{\circ}$ 205 del CdE de 2008 recoge una breve referencia a la publicidad activa (art. 10). 
en la administración pública», informando de derechos a la ciudadanía y la Administración frente a sus inercias. Se señala también que la ley ha de obligar a otorgar recursos a los objetivos de transparencia. Estos principios se proyectaron con claridad para América Latina en los Principios de Lima de 16 de noviembre de 2000 (el $4^{\circ}$, aboga por «promover una cultura de transparencia») ${ }^{108}$ y en la Declaración de los relatores de 2004. En todo caso, llama la atención que la obligatoriedad de capacitación de agentes públicos que es consecuencia del fallo de la SCIDH Claude Reyes de 2006 (§163-165) ${ }^{109}$. La Recomendación de 21 de febrero de $2002 \mathrm{CdE}$ (ap. X) y el Convenio no 205 del CdE de 2008 prevén como «medidas complementarias» (art. 9) la información a los ciudadanos y las acciones de formación a la administración.

\section{Obligación general del Estado de cumplir con las normas mínimas de gestión de archivos}

Entre las obligaciones de los Estados a resultas del derecho de acceso a la información es también habitual la afirmación del cumplimiento de normas mínimas de gestión de archivos. En el marco de CdE cabe tener en cuenta la Recomendación del Consejo de Ministros del CdE no 13, de 13 de julio de 2000, sobre política europea en materia de acceso a archivos ya partía de un principio de libre acceso. Y la Recomendación de 21 de febrero de 2002 del Comité de Ministros del CdE afirmaba unas «Medidas complementarias» (X) especialmente en gestión y archivos, al igual que el Convenio no 205 del CdE de 2008 en su artículo 9 impone $« c)$ gestionar sus documentos eficientemente de modo que sean fácilmente accesibles»; «d) seguir los procedimientos claros y preestablecidos para la preservación y destrucción de sus documentos. La gestión de archivos es el cimiento de una buena transparencia ${ }^{110}$ pese a que sea habitualmente ignorada por los juristas. Esta obligación general internacional debe acabar proyectándose incluso en la adopción de políticas de transparencia desde el inicio del diseño del ciclo de vida y gestión documental ${ }^{111}$.

108 El Estado está en la obligación de promover una cultura de transparencia en la sociedad y en el sector público, de actuar con la debida diligencia en la promoción del acceso a la información, de identificar a quienes deben proveer la información, y a prevenir los actos que lo nieguen y sancionar a sus infractores.

109 No en vano, la sentencia obliga a adaptar el derecho interno y a «realizar, en un plazo razonable, la capacitación a los órganos, autoridades y agentes públicos encargados de atender las solicitudes de acceso a información bajo el control del Estado sobre la normativa que rige este derecho, que incorpore los parámetros convencionales que deben respetarse en materia de restricciones al acceso a dicha información». (\$163-165)

110 En España destacan los estudios en Tabula: revista de archivos de Castilla y León, nº 15,2012 (monográfica sobre transparencia) así como Lligall, Revista Catalana D'Arxivística, $\mathrm{n}^{\circ} 38,2016$.

111 En especial, Cerrillo Agustí y Casadesús ANAhí, «La transparencia por diseño: el impacto de la gestión documental en la transparencia pública», ponencia GIGAPP, VII Congreso Internacional en Gobierno, Administración y Políticas Públicas. GIGAPP 03-05 octubre 2016 y, por mi parte, «Una nueva 


\section{GARANTÍAS A SU EJERCICIO: UN ACCESO SIN INTERÉS LEGÍTIMO, SIN BARRERAS, ÁGIL, SENCILLO, SIN TRABAS ECONÓMICAS Y CON RECURSOS EFECTIVOS ADMINISTRATIVOS Y JUDICIALES}

\section{No es necesario acreditar un interés legítimo para el acceso a la información pública, pero es mejor motivar la solicitud}

Una de las claves del derecho de acceso a la información como derecho fundamental y vinculado al principio de máxima transparencia es que no se requiere un interés legítimo o directo para solicitar información. En el marco de la ONU, el Dictamen CDN del caso Nurbek Toktakunov vs. Kirguistán ${ }^{112}$ lo afirma expresamente $^{113}$, al igual que en el ámbito de América Latina la SCIDH Claude Reyes de $2006(\$ 77)^{114}$, lo cual se reitera en la SCIDH Gomes Lund y otros vs. Brasil de 24 de noviembre de 2010 ( $\$ 197$ ). La Recomendación de 21 de febrero de 2002 del Comité de Ministros del CdE (V) y en el Convenio n ${ }^{\circ} 205$ del CdE de 2008 (art. $4.1^{\circ}$ ) reconoce que los estados pueden permitir el anonimato, salvo que la «la identificación sea esencial para procesar la petición». Por su parte el artículo 6. $1^{\circ}$ del Reglamento $\mathrm{n}^{\circ}$ 1049/2001 de la UE es claro: «El solicitante no estará obligado a justificar su solicitud.» El TJUE ya lo había afirmado desde $1998^{115}$.

Ahora bien, aunque la expresión de las causas y justificaciones para solicitar el acceso no es necesaria, puede ser un elemento muy útil para que se pueda apreciar el interés público que haga prevalecer el derecho de acceso frente a diversas excepciones o derechos que puedan concurrir. De ahí que sin ser obligatorio determinar la finalidad para la que se pretende la información, la relevancia que puede llegar a tener la información solicitada — que en ocasiones no se deduce por sí misma-, así como la conexión de lo anterior con la naturaleza del solicitante de información puede conllevar el reforzamiento y protección del acceso y su fundamentalidad misma. La jurisprudencia en la UE y del TEDH se van decantando en esta dirección ${ }^{116}$.

gestión documental electrónica para una futura transparencia por defecto e inteligente en la regulación de Colombia y España» (en prensa).

112 Comunicación $\mathrm{N}^{\circ}$ 1470/2006, 28 de marzo de 2011.

113 «se debe proporcionar la información sin que sea necesario probar un interés directo o una participación personal para obtenerla, salvo en los casos en que sea aplicable una restricción legítima» (§ 6.3 y ss.).

114 «La información debe ser proporcionada sin necesidad de comprobar interés directo ni relación personal para obtenerla, exceptuándose los casos en los cuales sea aplicable una restricción legítima» (§ 77).

115 Así, sentencia del antiguo Tribunal de Primera Instancia caso Van der Val de 19 de marzo de 1998 en el asunto T-83/1996, Gerar Van der Wal/ Comisión $(\$ 41)$ y el mismo tribunal en el caso Svenska Journalistförbundet/Consejo de la Unión (T-174/95), de 17 de junio de 1998 (§ 65-66).

116 Por una parte, en la UE, la STJUE del caso Comisión v. Bavarian Lager, asunto C-28/08 P, de 29 de junio de 2010 recuerda que el solicitante tiene que «demostrar» la necesidad de la transmisión de los datos personales que solicita ( $\$ 78$ ). Recientemente interesa la STGUEde 15 de julio de 2015, Gert-Jan Dennekamp contra Parlamento Europeo en la que fue decisivo que el solicitante señalara porqué quería saber los 


\section{Las barreras al acceso pueden ser censura. El procedimiento de acceso ha de ser ágil, con garantías y sencillez}

Sobre la base de la libertad de expresión, la STHED Társaság a Szabadságjogokért contra Hungría, de 14 de julio de 2009 subraya que las barreras al acceso a la información pública pueden ser una forma de censura, y deben ser sometidas a un control especialmente riguroso ( $\$ 36$ y 38). Y siguendo al TEDH, si la Administración dice que no se tiene información, ha de ser «convincente», pues lo contrario es «arbitrariedad ${ }^{117}$. La STEHD de 8 de noviembre de 2016 caso Magyar recuerdan que la negligencia en el tratamiento de la información por la Administración no es excusa para facilitar la información que existe y está disponible (\$169).

El procedimiento de acceso ha de ser simple, ágil, rápido y con garantías. Ello se afirma como Principio 5 del los Principios de la organización «Artículo $19 »^{118}$ y estas exigencias se proyectan en las mencionadas «normas de la ONU» de 2004 (Principio 4). En la Declaración de los relatores de $2004^{119}$ expresamente se afirma que «el proceso para acceder a la información deberá ser simple, rápido y gratuito o de bajo costo.» La Observación general no 34 del CDH de 2011 ( $§$ 19) exige un «Acceso fácil» con trámites rápidos y claros. El Dictamen CDN del caso Nurbek Toktakunov vs. Kirguistán ${ }^{120}$ afirma la obligación de que «los Estados Partes deben hacer todos los esfuerzos para garantizar el acceso fácil, rápida, efectiva y práctica a dicha información ( $\$ 7$, con remisión a su Observación General no 34).

En Europa, la mayoría de estas exigencias se reflejan en las disposiciones de la Convención de Aarhus (en especial en el art. 4). En el ámbito del Consejo de Europa, tanto en la Recomendación de 21 de febrero de 2002 (V. II y VI) como en el Convenio no 205 del CdE de 2008 (arts. 4.3 y 5) ${ }^{121}$. Asimismo, el acceso ha de ser en el

nombres de diputados ( $\$$ 82). Por otra parte, la STEHD de 8 de noviembre de 2016 caso Magyar como se ha expuesto, hace girar la conexión con la libertad de expresión con la finalidad del acceso a la información.

117 STEDH Youth Initiative for Human Rights c. Serbia, de 25 de septiembre de 2013, tras una orden del Comisionado de Información que obligaba al gobierno a dar la información, éste comunicó a la demandante que no poseía esa información. Al respecto, el TEDH entiende que «no es convincente» (\$25) y que mostraba real «arbitrariedad» (\$ 26). En sentido similar (aunque también en juego el art. 6 CEDH), se afirma de «arbitrariedad» por resistencia a facilitar la información en la STEDH Kenedi v. Hungría, de 26 de agosto (\$ 45).

118 ONG «Art. 19», «El derecho de saber del público: Principios ... cit. Así, «Las solicitudes de información se tramitarán rápida e imparcialmente». Ha de haber «sistemas internos abiertos y accesibles»; «los órganos designarán a una persona que se encargará de dar curso a estas solicitudes y de garantizar el cumplimiento de la ley». Asimismo es necesario que «los órganos públicos ayuden a [...] reformular solicitudes» si es necesario. También se reconoce «la posibilidad de rechazar las solicitudes frívolas o insultantes». Y la obligación de imponer "plazos estrictos para tramitar las solicitudes y exigirá que toda denegación se justifique».

119 Declaración Conjunta, cit.

120 Comunicación $N^{\circ}$ 1470/2006, 28 de marzo de 2011.

121 Por cuanto al procedimiento de acceso, la Recomendación de 21 de febrero de 2002 del Comité de Ministros del CdE indica que las formalidades para solicitar el acceso han de ser las «mínimas» (V. II) y la tramitación (VI) ha de ser «con prontitud». La Administración «no tiene la obligación de cumplir 
«formato que elija» el solicitante (art. 6.1) salvo que se remita a «fuentes alternativas fácilmente accesibles» $(\text { art. 6.3 })^{122}$. En la UE, el ejercicio del derecho de acceso a la información bajo estos principios está ampliamente recogido en el Reglamento $\mathrm{n}^{\circ}$ 1049/2001: plazos breves de resolución (15 días, art. 7.1 y 3), silencio positivo (art. 7.4), posible llegar a acuerdos (art. 6.3) y solicitar aclaraciones (art. 6.2) y pocas formalidades. El solicitante puede pedir el acceso directo a la información o a una copia (art. 10.1) o que se remita a donde esté publicada (art. $7.2^{\circ}$ ). Llama la atención que ya en 2001 se posibilitara el ejercicio electrónico y se regulara la integración de información en registros electrónicos (art. 12) ${ }^{123}$.

\section{El procedimiento de acceso ha de ser gratuito o a precios razonables y que no disuadan}

Por cuanto a la gratuidad, internacionalmente no se recoge una regulación como la de la Freedom of Information Act de EEUU por la cual hay una exención de tasas para casos vinculados con el interés público ${ }^{124}$. El Principio 5 de los de la organización «Artículo 19» afirma que las «solicitudes de información no deberá entrañar un coste excesivo que actúe como factor disuasorio». Además de no superar el coste real, se afirma que «debería suprimirse o reducirse considerablemente [el coste] para las solicitudes de información personal o de interés público» y, por el contrario, «tarifas más altas a las solicitudes comerciales». El Informe de la ONU del año 2000 («normas de la ONU», Principio 4) señala que los costos «no deben ser tan altos que desmotiven a potenciales solicitantes, negando la intención de la

con la solicitud si se trata de un documento que no puede ser identificado», y en todo caso, para la denegación «debe dar las razones de la razones de la negativa.» Ello se proyecta con claridad en el Convenio ${ }^{\circ}$ 205 del CdE de 2008, que prescribe que las formalidades para el ejercicio del derecho deben ser las esenciales (art. 4. 3). Igualmente se debe asistir al solicitante (art. 5.1) y tramitarse con «prontitud» (art. 5.5). Cualquier denegación debe ser motivada con derecho a exigir respuesta escrita (art. 5.6). Si el documento no lo tiene o no tiene autoridad la Administración a quien se haya solicitado, habrá de remitir al competente (art. 5.2).

122 «3) La autoridad pública puede dar acceso a un documento oficial remitiendo al solicitante a fuentes alternativas fácilmente accesibles.»

123 En el Reglamento $n^{\circ}$ 1049/2001 la novedad (tratándose del año 2001) se daba también por la integración de las solicitudes y acceso a los registros por medios electrónicos. Esta posibilidad, obviamente dota de gran eficacia y realidad a la posibilidad de ejercicio del derecho de acceso. El registro público es obligatorio, no así su acceso por medios electrónicos («se debería facilitar» según el art. 11.1 y art. 12 «en la medida de lo posible»). Se insiste en facilitar por estos medios la información de los procesos legislativos (art. 12. 2). El registro incluye una serie de información mínima, siempre sin perjudicar los intereses protegibles (art. 11. 2). No obstante, se ha censurado que la exigencia de registro de toda documentación no es rotunda y permite esconder la existencia de algunos documentos (como en el caso de los documentos sensibles).

124 Se da dicha exención si «la divulgación de la información es de interés público, ya que es probable que contribuya significativamente a la comprensión pública de las operaciones o actividades del gobierno y no es principalmente comercial el interés del solicitante «. 5 USC $\$ 552$ (a) (4) (A) (iii). Sobre la FOIA, por todos, U.S. DEPARTMENT OF JUSTICE, Guide to the Freedom Of Information Act, https://www.justice.gov/oip/ doj-guide-freedom-information-act-O 
misma ley». Para Europa, el Convenio de Aarhus en su artículo 4. $8^{\circ}$ se habla de una «cuantía razonable» en todo caso transparente, con posibles exenciones. El principio de gratuidad o que al menos la tasa no supere el coste se contempla en la Recomendación de 21 de febrero de 2002 del Comité de Ministros del CdE (VIII). El artículo 7 del Convenio n 205 del CdE de 2008 añade que «Las tarifas deberán estar publicadas» (art. 7. $2^{\circ}$ ). El Reglamento n ${ }^{\circ}$ 1049/2001 de la UE recoge las mismas garantías, incluso la gratuidad hasta 20 páginas (art. 10. $1^{\circ}$ ).

\section{La garantía judicial y ante una autoridad independiente como parte del derecho}

Internacionalmente uno de los elementos básicos del derecho de acceso a la información es garantizar la existencia de una vía efectiva de recurso previo, evitando la vía judicial por lo general lenta y costosa. Ello se afirmó con claridad en el Principio 5 los Principios de la ONG «Artículo 19» ${ }^{125}$. No obstante, las afirmaciones internacionales son muy discretas y sólo en Europa se da importancia a la garantía administrativa independiente. Así, a nivel mundial, la Declaración de los relatores de 2004 afirma que ha de haber un recurso «ante un órgano independiente con plenos poderes para investigar y solucionar dichos reclamos». Por su parte, la Observación general no 34 del CDH de 2011 simplemente afirma que «habría que establecer» recursos ( $\$ 19)$. El Convenio de Aarhus de 1998 garantiza esencialmente un recurso judicial. La SCIDH Claude Reyes de 2006 deja claro que es necesario el acceso sencillo, rápido y efectivo a la justicia frente a las denegaciones de información (\$ 137), en la línea de lo dispuesto para los derechos del CIDH (art. 2 y 25.2.b). Y si «no tiene un recurso judicial para proteger efectivamente el derecho tiene que crearlo.» (§ 137). Respecto de la garantía ante una Administración, ésta se afirma como principio $8^{\circ}$ de los Principios sobre acceso a la información de la OEA de 2008.

En el marco del Consejo de Europa, la Recomendación de 21 de febrero de 2002 afirma el «acceso a un recurso ante un tribunal judicial o ante otro órgano independiente e imparcial establecido por la ley» $\mathrm{y}$, asimismo «debe tener siempre acceso a un procedimiento de revisión expedita y económica» ya por una autoridad pública o judicial (IX). Ello tiene claro reflejo en el Convenio no 205 del CdE de

125 ONG «Art. 19», «El derecho de saber del público: Principios ... cit. Una vez más, cabe partir de los Principios de la ONG «Art. 19», concretamente, el Principio 5 incluye el «derecho individual de apelar ante un órgano administrativo independiente», garantizada "por el procedimiento de designación de su jefe o de los integrantes de su junta directiva», que habrá de contar con «profesionalidad, independencia y capacidad». El recurso será «ágil y lo menos costoso posible». La autoridad deberá tener plenas facultades para investigar, con posibles testigos, poder de «obligar al órgano público a proporcionar la información» e incluso «la facultad de remitir a los tribunales los casos en los que haya pruebas de obstrucción ilícita del acceso o destrucción intencional de documentación.» Las denegaciones de esta autoridad serán recurribles judicialmente. 
2008 que reconoce el «acceso a un procedimiento de reclamación antes de la apelación ante un tribunal u otra institución independiente e imparcial establecida por la ley» (art. $8.1^{\circ}$ ), con proceso de «apelación rápido y barato, que implique la reconsideración» (art. 8. $2^{\circ}$ ). Por su parte, el Reglamento $n^{\circ}$ 1049/2001 de la UE, en caso de denegación total o parcial se dispone de «el recurso judicial contra la institución y/o la reclamación ante el Defensor del Pueblo Europeo» (art. 10. $1^{\circ}$ ).

\section{LOS REQUISITOS DE LOS LÍMITES AL DERECHO DE ACCESO Y SU CONFLICTO CON LA PROTECCIÓN DE DATOS ESPECIALMENTE EN LA UNIÓN EUROPEA}

\section{Las excepciones al acceso en el ámbito mundial}

Dado que el derecho de acceso a la información pública se inserta en el contenido de la libertad de expresión e información, se proyectan las exigencias respecto de los límites a estas libertades: las fijadas por la ley, con objetivos legítimos necesarios y que resulten proporcionales siguiendo lo dispuesto por el artículo 19. $3^{\circ}$ PIDCP. Y la Observación general n 34 del CDH de 2011 respecto de la «Aplicación del párrafo 3 del artículo 19» (\$ 21-36) señala de manera precisa cómo deben ser interpretados y aplicados los límites, también para el de acceso a la información pública. Un ejemplo de la aplicación se da en el Dictamen CDN del caso Rafael Rodríguez Castañeda vs. México de 2012 (§ 7.5). ${ }^{126}$

Respecto de los requisitos de límites en el ámbito internacional, destaca el Principio 4 de los Principios de la ONG «Artículo 19»: criterio de «daños»e «interés público» para admitir una excepción, sometimiento a un test de «tres condiciones estrictas»: $1^{\circ}$, restricciones expresas y «bien definidas en la ley», si es posible «sujetas a un plazo»; $2^{\circ}$, prueba daño real a un fin legítimo por difusión de la información y, $3^{\circ}$, que «El daño potencial deberá ser mayor que el interés público de la divulgación». Además, siguiendo el Principio 8, hay interpretar otras leyes de conformidad al derecho de acceso y «si no es posible, modificarlas o derogarlas». Siguiendo estos principios, las «normas de la ONU» de 2000 son claras: «las limitaciones a los archivos en poder del Estado deben ser excepcionales. Éstas deben estar claramente establecidas en la ley y aplicables sólo en el caso que exista un peligro real e inminente», analizadas en cada caso ( $\$ 20)$. Estos principios se recogen también en la Declaración de los relatores de 2004, además, las leyes deben definir «con exactitud el concepto de seguridad nacional y especificar claramente los criterios» y han de señalar con claridad el sistema de clasificación y los plazos del secreto.

126 Comunicación 2202/2012, CDN, caso Rafael Rodríguez Castañeda vs. México, de 18 de julio de 2013. 
El artículo 4. $4^{\circ}$ del Convenio de Aarhus regula las limitaciones al derecho sobre la base de una serie de causas que «deberán interpretarse de manera restrictiva teniendo en cuenta el interés que la divulgación de las informaciones solicitadas tendría para el público y según que esas informaciones guarden o no relación con las emisiones en el medio ambiente.» En América Latina, la siempre relevante SCIDH Claude Reyes de 2006 aborda con cierta profundidad la cuestión de los requisitos a los límites al derecho, sobre la base de los límites al artículo $13 \mathrm{CADH}^{127}$.

\section{Los límites al acceso a la información en Europa y la importante labor jurisprudencial}

Al igual que los límites a la libertad de expresión del artículo $10 \mathrm{CEDH}$, los límites al derecho de acceso a la información han de ser por ley, necesarios en una sociedad democrática y proporcionales ${ }^{128}$. Y debe recordarse que procede el escrutinio severo que corresponde a esta libertad por su dimensión pública. A ello hay que añadir que en la STHED Társaság a Szabadságjogokért contra Hungría, de 14 de julio de 2009, la barrera de acceso a la información se vincula la negación de la información a cierta «censura» con un escrutinio aún más severo (§ 36$)$.

En la Recomendación de 2002 del Comité de Ministros del CdE respecto de las limitaciones (IV), se afirma una lista de finalidades legítimas, que se concretan en el artículo $3.1^{\circ}$ del Convenio n ${ }^{\circ} 205$ del CdE de 2008. Se prevé que se puedan ampliar las excepciones respecto de comunicaciones con el Jefe de Estado ${ }^{129}$. No obstante, también se indica que un «interés público» puede prevalecer sobre estas causas a favor del acceso a la información pública (art. 3. $2^{\circ}$ ). Los Estados «considerarán» si fijar plazos respecto de los límites (art. 3. $3^{\circ}$ ).

En la UE, con el Reglamento 1049/2001 se unificó el sistema de excepciones frente a la anterior dispersión normativa. Las excepciones se dividen según los

127 Si no se siguen estos requisitos se cae en «la actuación discrecional y arbitraria del Estado (§98). Se parte del «principio de máxima divulgación, el cual establece la presunción de que toda información es accesible, sujeto a un sistema restringido de excepciones.» (\$ 92). En virtud de este principio «93. Corresponde al Estado demostrar que al establecer restricciones al acceso a la información bajo su control ha cumplido con los anteriores requisitos.» (\$ 93, ver también § 95). Asimismo la denegación debía haber sido motivada, lo contrario afecta «la posibilidad de realizar un control social de la gestión pública.» (\$ 99). La sentencia del caso Gomes Lund y otros vs. Brasil de 24 de noviembre de 2010 reitera la necesidad de motivar los límites ( $\$ 197)$. El art. 41 de la Ley modelo regula de manera bastante precisa las «excepciones» por intereses privados, públicos o por confidencialidad de las comunicaciones.

$128 \mathrm{Al}$ respecto y con claridad, FreiXes SANJuÁN, T.: «Las principales construcciones jurisprudenciales del Tribunal Europeo de Derechos Humanos: El standard mínimo exigible a los sistemas internos de derechos en Europa», Cuadernos constitucionales de la Cátedra Fadrique Furió Ceriol, no 11-12, 1995, pp. 97-115, acceso completo en https://goo.gl/1VuQP4

129 Los Estados interesados, a la hora de la firma o al depositar su instrumento de ratificación, aceptación, aprobación o adhesión, mediante una declaración enviada al Secretario General del Consejo de Europa, pueden declarar que las comunicaciones oficiales con la Familia Real y su Casa Real o el Jefe de Estado también están incluidas entre las posibles limitaciones. 
bienes a proteger a lo largo del artículo $4^{130}$ y perduran mientras se dé la justificación, hasta un máximo de 30 años (art. 4. 7. $^{\circ}$ ). Este plazo incluso puede ampliarse respecto de la protección de la intimidad, intereses comerciales y documentos sensibles. Precisamente, tales «documentos sensibles» constituyeron una novedad, criticada desde diversos sectores. Los documentos sensibles se clasifican en tres niveles y van dirigidos a preservar, en particular, «la seguridad pública, la defensa y los asuntos militares» (artículo 9. $1^{\circ}$ ), y sobre los mismos se incrementan sus garantías de opacidad ${ }^{131}$.

Aunque la jurisprudencia de la UE no ha subrayado el carácter de derecho fundamental del derecho de acceso a la información pública y sólo lo ha mencionado en 2015, ya en 1997 se afirmó que los límites han de ser interpretados restrictivamente ${ }^{132}$. Y en los últimos años se aprecia si cabe una interpretación más restrictiva de las excepciones. En este sentido, es lugar común en la jurisprudencia la referencia a la STJUE de 18 de diciembre de 2007, Suecia/Comisión, C 64/05: «el derecho de acceso del público a los documentos de las instituciones está ligado al carácter democrático de éstas $[\ldots .$.$] las excepciones a este derecho$ enumeradas en su artículo 4 deben interpretarse y aplicarse en sentido estricto». $(\S 66)^{133}$. También es cierto que los tribunales de la UE que han decantado unos nueve supuestos en los que se presume que sí que concurren motivos para denegar el acceso a la información ${ }^{134}$.

Bajo el criterio de restricción de todo límite, la jurisprudencia ha afirmado diversas garantías aparejadas a este derecho: —es obligatoria la ponderación del

130 Así, «el interés público, por lo que respecta a: la seguridad pública, la defensa y los asuntos militares, las relaciones internacionales, la política financiera, monetaria o económica de la Comunidad o de un Estado miembro (art. 4.1 a); la intimidad y la integridad de la persona, en particular de conformidad con la legislación comunitaria sobre protección de los datos personales (art. 4. 1 b); los intereses comerciales de una persona física o jurídica, incluida la propiedad intelectual (art. $4.2^{\circ}$ ); los procedimientos judiciales y el asesoramiento jurídico (art. 4. 2); el objetivo de las actividades de inspección, investigación y auditoría (art. 4. 2); salvo que su divulgación revista un interés público superior (art. 4. 2); protección de la toma de decisiones, siempre que pueda «perjudicar gravemente» la misma y salvo interés público superior (art. 4. 3).

131 Sólo personal autorizado tiene acceso a ellos y se permiten particularidades de lo que sobre ellos debe constar en el registro, incluso su no inclusión (art. 9. 2 y 3). La motivación en la denegación a estos documentos no puede descubrir su contenido (art. 9. 4)

132 Por todas, la importante sentencia del caso WWF del Tribunal de Primera instancia de 1997, donde se recuerda que las excepciones al acceso deben interpretarse de tal manera que no hagan imposible alcanzar el objetivo de transparencia perseguido por la Decisión. (§ 57) y opera un repaso interpretativo a los tipos de excepciones de la Decisión 94/90 que entonces regulaba el acceso. Un análisis exhaustivo de los límites, Guichot Reina E.: Transparencia y acceso a la información en el derecho europeo, cit. pp. 135-229.

133 Así, se «en relación con la regulación anterior al Reglamento n 1049/2001, las sentencias de 11 de enero de 2000, Países Bajos y Van der Wal/Comisión, C174/98 P y C189/98 P, Rec. p. I1, apartado 27, y Consejo/Hautala, antes citada, apartados 24 y 25, así como, por lo que respecta al Reglamento $\mathrm{n}^{\circ}$ 1049/2001, la de 1 de febrero de 2007, Sison/Consejo, C266/05 P, Rec. p. I1233, apartado 63).» A éstas cabe añadir, entre otras, la STG de 22 de marzo de 2011 asunto T233/09, caso Access Info Europe y la STJUE de 3 de julio de 2014, asunto C350/12 P caso Sophie in 't Veld.

134 Estos supuestos los resume la reciente STGUE de 26 de mayo de 2016 International Management Group contra Comisión Europea, en sus apartados 29 y 30. 
interés en la difusión de la información con otros intereses en litigio, acotando la discrecionalidad de las instituciones para llevar a cabo tal juicio ${ }^{135} ;$ - a favor de dar la información hay que tener en cuenta siempre «las ventajas que se derivan[...] de una mayor apertura, a saber, una mayor participación de los ciudadanos en el proceso de toma de decisiones y una mayor legitimidad, eficacia y responsabilidad de la Administración para con los ciudadanos en un sistema democrático (STJUE Suecia y Turco/Consejo ap. 45); — cuando se trata de información relativa a la actividad legislativa (del Parlamento o del Consejo) se refuerza la transparencia exigible y su prevalencia en la ponderación (STJUE Suecia y Turco/Consejo ap. 45); - la motivación de la denegación o acceso parcial ha de ser escrita y no ha de ser meramente formal, y que ha de versar sobre cada uno de los documentos a los que se deniega el acceso (o en su caso respecto de cada categoría de los documentos solicitados) ${ }^{136}$; — la interpretación y fiscalización de cuáles son los «intereses» contrarios al acceso también ha sido restrictiva, siendo que el interés público contrario a la información debe ser «razonablemente previsible y no puramente hipotético». Quien deniega la información «debe también explicar la razón por la que el acceso al citado documento podría perjudicar concreta y efectivamente el interés protegido» ${ }^{137}$; - no basta relacionar la información solicitada con una de las excepciones, quien deniega «debe también explicar la razón por la que el acceso al citado documento podría perjudicar concreta y efectivamente el interés protegido por una excepción prevista en dicho artículo (STUE de 27 de febrero de 2014 Comisión/EnBW, C365/12 P, ap. 64). «Además, el riesgo de dicho menoscabo debe ser razonablemente previsible y no puramente hipotético» ${ }^{138}$; - la restricción de los límites se observa cuando el Tribunal restringe y mucho la posibilidad de que el acceso a la información quede limitado por razones materiales

135 Así en la sentencia Caso Carvel y Guardian Newspapers contra el Consejo Sentencia Tribunal de Primera Instancia, T-194/94, 19 de octubre de 1995 (\$ 65), subrayando que la falta de ponderación produce la nulidad ( $\$ 75$ y 78). También, entre otros, en el caso Svenska Journalistförbundet/Consejo de la Unión (T-174/95), Tribunal de Primera Instancia, de 17 de junio de 1998 (§ 122).

136 Así, por ejemplo, en el citado caso Svenska (§ 125). También en el caso WWF UK/Comisión, T-105/95 sentencias de 5 de marzo de 1997. En caso JT's Corporation/Comisión, (T-123/99), sentencia de 10 de diciembre de 2000, aunque con contradicciones respecto del caso WWF. También en Caso David Petrie y otros contra la Comisión (T-191/99), sentencia del Tribunal de Primera Instancia, de 11 de diciembre de 2001. Ha habido muchos casos posteriores. En casi todos los asuntos se da un análisis profundo de la suficiencia de la motivación conferida a la denegación.

137 STJUE Comisión/EnBW, C365/12 P, § 64 y en STJUE de 16 de julio de 2015, asunto C 615/13 P, ClientEarth y PAN Europe vs. Autoridad Europea de Seguridad Alimentaria (EFSA) y Comisión Europea (\$ 68).

138 Así se afirma con relación a la «seguridad pública» en el citado caso Svenska de 1998 (\$121). Resulta particularmente significativa de la estricta interpretación del interés contrario a la transparencia en la sentencia de caso Aldo Kuijer/Consejo II, (T-211/00), st. del Tribunal de Primera Instancia de 7 de febrero de 2002 (en especial $§ 57$ y $§ 64$ ). En los últimos años, STJUE Suecia y Turco/Consejo de 21 de septiembre de 2010, C-39/05 P y C-52/05 P ap. 43), recientemente, STJUE de 17 de octubre de 2013, C-280/11 P, Consejo/Access Info Europe (ap. 30. 
de carga a la administración, por cuanto permitir el acceso pudiese mermar su eficacia y eficiencia ${ }^{139}$.

Igualmente, a la vista de este criterio de restricción de todo límite, se han configurado reglas como que pese a que se trate de documentación administrativa en posesión judicial en razón de un proceso, debe poder accederse a ella en tanto en cuanto es administrativa, salvo que el juez esté en contra y le afecte el secreto ${ }^{140}$. Los casos que están bajo investigación comunitaria caben entre las excepciones de interés público ${ }^{141}$, pero ello no puede suponer la imposibilidad de acceder a toda la documentación por este simple motivo, sino que se ha de analizar el marco concreto de investigación, la fase del proceso, el tipo de documento, etc. ${ }^{142}$

\section{El conflicto del derecho de acceso con la intimidad y protección de datos, especialmente en la UE}

Puede afirmarse que el nivel de protección de la privacidad y protección de datos en Europa, y especialmente en la UE es un nivel alto y superior al de otras regiones del mundo. Y el conflicto de la intimidad y protección de datos con el acceso a la información ha sido por ello objeto de atención en la UE, lo cual no ha sucedido en el ámbito internacional o en América Latina. En la UE el derecho a la protección de datos personales llegó antes que el derecho de acceso a la información. Como consecuencia, el primero parece contar con cierta prevalencia en la ponderación por los tribunales, si bien parece que esta prevalencia está siendo corregida.

El primer caso de referencia fue la STJUE del caso Comisión v. Bavarian Lager, asunto C-28/08 P, de 29 de junio de 2010, relativa al acceso a la identidad de los representantes de intereses que se reúnen con la Comisión. La Comisión pidió el consentimiento de los afectados, que no obtuvo y denegó finalmente la información solicitada; además no pudo hacer una ponderación por no saber motivos de los solicitantes para requerir la identidad. El solicitante tiene que «demostrar» la necesidad de la transmisión de los datos personales que solicita ( $\$$ 78). Frente a la sentencia del Tribunal de Primera instancia (que reconoció el derecho de acceso a la información), el TJUE avaló la denegación de la Comisión.

139 Así, esta posible limitación se admite en la st. del Tribunal de Primera Instancia caso Hautala ( $\S$ 86) y se confirma en la st. del Tribunal de Justicia ( $(30)$. Resultas significativas las conclusiones del Abogado General por cuanto insiste en las «cautelas» a la hora de admitir estos límites en razón de las cargas administrativas (\$ 118-121).

140 Tribunal de Primera Instancia caso Van der Val (\$ 49-50) y sobre todo, la st. del Tribunal de Justicia relativa a este caso ( $\$ 24$ a 32). Asimismo esta regla se observa en el caso Interporc II ( $\$ 38$ y ss.). Puede seguirse también, en el caso JT.

141 Ejemplo, el citado caso WWF.

142 Ejemplo, casos citados Bavarian Lager/Comisión (T-309/97) en primera instancia y Denkavit Nederland/Comisión (T-20/99). 
El caso evidenció la falta de una regulación concreta de este conflicto de derechos y la escasa armonía entre el Reglamento 1049/2001 y el Reglamento 45/2001 que regula la protección de datos para las instituciones y órganos de la UE.

De nuevo se aprecia una prevalencia de la protección de datos en la STJUE caso Volker und Markus Schecke de 9 de noviembre de 2010. Se trataba de la publicación en internet de los nombres y cantidades recibidas por los beneficiarios de distintos fondos de la UE, algo que estaba regulado y las personas subvencionadas firmaban una declaración en la que les constaba que era obligatorio publicar los datos de esas concretas ayudas. Sin embargo, la sentencia afirma que «no cabe atribuir una primacía automática al objetivo de transparencia frente al derecho a la protección de los datos de carácter personal (véase en este sentido la sentencia Comisión/Bavarian Lager, antes citada, ( 75 a 79), ni siquiera aunque estén en juego intereses económicos importantes» (\$ 85). Entendió que es necesario discriminar la información que se publica en internet $(\S 79, \S 89){ }^{143}$ por lo que se anularon las normas de transparencia activa ( $\$ 85)$.

Esta primacía de la privacidad se mitiga con la STJUE de 16 de julio de 2015, asunto C 615/13 P, ClientEarth y PAN Europe vs. Autoridad Europea de Seguridad Alimentaria (EFSA) y Comisión Europea ${ }^{144}$. El TJUE entiende especialmente importante la revelación de los nombres de unos dado el contexto de desconfianza en procesos decisionales en los que habían participado, con gran presencia de lobbies ( $\$ 53)$. Se afirma que estos procesos quedan legitimados si se da una efectiva transparencia ( $\$ 56)$. En concreto, la información sobre la identidad que se denegó era «necesaria para comprobar en concreto la imparcialidad de cada uno de los expertos» ( $\$ 58)$. Haber facilitado dicha información hubiera disipado las dudas existentes respecto del proceso de decisiones (§ 69). En sentido similar, la STGUE de 15 de julio de 2015, Gert-Jan Dennekamp contra Parlamento obliga a facilitar los nombres de unos parlamentarios implicados en la solicitud de información en la que el solicitante motivaba la necesidad ${ }^{145}$.

La nueva etapa abierta por la STEHD de 8 de noviembre de 2016 caso Magyar se ha iniciado precisamente en el ámbito del conflicto con la protección de datos. Y debe señalarse que la impronta clara es que cuando se trata del artículo $10 \mathrm{CEDH}$ por la relevancia pública de la finalidad, de la información solicitada y

143 El TJUE considera que «la publicación, en un sitio web único por Estado miembro y de consulta libre, de los datos nominales de todos los beneficiarios afectados y de los importes específicos procedentes [...] sin establecer diferencias en función de la duración de las ayudas percibidas, de su frecuencia, o del tipo o magnitud de las mismas_ _ iba más allá de lo necesario para alcanzar los objetivos legítimos perseguidos» (\$ 79).

144 La EFSA denegó a las empresas del sector la información solicitada relativa al nombre de los expertos externos que habían presentado ciertas observaciones en el proceso de decisión de un acto.

145 Se afirma que cuando el solicitante demuestra su necesidad de los datos y la institución no aprecia daño a intereses legítimos y no hay otra excepción en juego, deben facilitarse los datos solicitados (§ 65). Facilitar la información nominal solicitada sobre parlamentarios era la medida más adecuada y es proporcionada (\$ 94) para «sacar a la luz conflictos de intereses potenciales de los diputados [...lo que] permite garantizar un mejor control de la actuación de los diputados y del funcionamiento de una institución de la Unión» (§ 126) 
del sujeto, es posible la prevalencia de este derecho frente al artículo $8 \mathrm{CEDH}$ (ver $§ 181-200$, en especial 193 y ss.).

\section{PARA CONCLUIR, LA NECESARIA INTERIORIZACIÓN DEL DERECHO COMO FUNDAMENTAL EN ESPAÑA}

A lo largo del análisis se han empleado fuentes internacionales y supranacionales. Bien es cierto, y como suele ser habitual respecto de derechos emergentes, en muchos casos se maneja soft law internacional no vinculante (informes, declaraciones o recomendaciones, etc.). Ello no impide que sean referentes para apoyar y estimular el reconocimiento del derecho de acceso a la información como integrante de un derecho reconocido como fundamental en España. En cualquier caso, y más allá de este soft law, hay claras interpretaciones autorizadas que ya reconocen este derecho como parte integrante de derechos humanos que son reconocidos como derechos fundamentales en España (como en el caso del Comité de Derechos humanos ONU que lo ubica en el marco del artículo 19 PIDCP). Y, especialmente no puede desconocerse la vinculación jurídica que tienen las interpretaciones auténticas de tratados de derechos humanos que realizan, para nuestro ámbito, el TJUE o el TEDH. En consecuencia, estas sentencias son obligados criterios interpretativos que determinan el contenido constitucional y perfil exacto de los derechos fundamentales en España en razón del artículo 10.2 CE (entre otras, STC 36/1991, FJ 4; STC 28/1991, $\mathrm{FJ} 5^{\circ}$ ). Estos referentes llevan a que sea inelubile la consideración total o parcial - del acceso a la información como derecho fundamental en España.

Según se ha visto, hay una doble vía de reconocimiento del acceso a la información pública en Europa. El acceso a la información se ha reconocido como un derecho autónomo en la UE (art. 42 CDFUE), si bien éste derecho no se corresponde con un derecho fundamental en la Constitución española. Además es limitado el alcance de la CDFUE al interior de España. De otro lado y para el TEDH, sólo si se dan unos requisitos, el acceso a la información pública forma parte la libertad de expresión e información que reconoce el artículo 10 CEDH. En consecuencia en Europa no coinciden bien ni los titulares, ni el ámbito de aplicación del derecho, ni la intensidad de protección. Estas divergencias van a generar algunos problemas de integración en España.

Pese a estas ciertas aristas, lo que no puede dudarse es que en razón del artículo $10.2^{\circ} \mathrm{CE}$, hay cuanto menos un muy importante mínimo del acceso a la información pública que está protegido por derechos fundamentales reconocidos como tales en España y que a lo sumo puede discutirse su alcance y magnitud. Es ineludible el reconocimiento a través de la libertad de expresión e información tras la referida STEHD de 8 de noviembre de 2016. Asimismo es clara la conexidad o concurrencia del acceso a la información con derechos fundamentales como el artículo $23 \mathrm{CE}$ (parlamentarios y conejales), artículo 28 (sindicalistas) o con el derecho de protección de datos respecto de solicitudes de datos sobre el solicitante, entre otros. Va a ser interesante 
observar —y en la medida de lo posible impulsar ${ }^{146}$ - el proceso de interiorización e integración de este derecho fundamental por nuestras administraciones y otros sujetos obligados y por nuestros tribunales. En cualquier caso y según se ha dicho, la concurrencia de derechos sólo puede ir en la dirección de intensificar la garantía y alcance del acceso a la información, nunca en sentido contrario. En la línea de lo que he sostenido en el marco del Consejo de transparencia de la Comunidad Valenciana, la Disposición adicional primera de la Ley 19/2013 puede canalizar la concurrencia de un régimen constitucional cualificado de acceso acceso a la información pública, que sería el régimen especial, y el régimen general de la ley sería de aplicación supletoria siempre que no vaya en menoscabo del derecho fundamental del que se trate.

Las carencias de la Ley 19/2013 no son pocas, especialmente por cuanto a las causas de inadmisión (art. 18) o la ponderación con el derecho de protección de datos (art. 15). A falta de un legislador adecuado ${ }^{147}$, las autoridades de transparencia primero y los tribunales después, son los principales encargados de digerir el estado internacional del acceso a la información.

TITLE: The recognition and international content of access to public information as a fundamental right

ABSTRACT: The study analyzes the gradual international and supranational recognition of the right of access to public information as a fundamental right. This is a very advanced process worldwide, and especially in Latin America and the EU. For the Council of Europe, beyond declarations and Convention 205, it is analyzed. Anycase the focus is on the ECHR's action since 2009 and, above all, its judgment of November 2016. The new test to know whether or not the right of access to information has the protection of fundamental right in each specific case is examined.

RESUMEN: El estudio analiza el paulatino reconocimiento internacional y supranacional del derecho de acceso a la información pública como un derecho fundamental. En el ámbito mundial y especialmente en América Latina y también en la UE es un proceso muy avanzado. Ello ha influido en los últimos años en el Consejo de Europa. Además de declaraciones y el Convenio 205, es especialmente significativa la acción del TEDH desde 2009 y, sobre todo, con su sentencia de noviembre de 2016. Se analiza el nuevo test para saber si el derecho de acceso a la información tiene o no la protección de derecho fundamental en cada caso concreto.

KEY WORDS: new fundamental rights, human rights, right of access to public information, freedom of expression, open government.

Palabras Clave: nuevos derechos fundamentales, derechos bumanos, derecho de acceso a la información pública, libertad de expresión, gobierno abierto.

FECHA DE RECEPCIÓN: 30.01.2017

FECHA DE ACEPTACIÓN: 26.07.2017

146 Entre otras acciones, la Declaración impulsada por Access Info y avalada por decenas de especialistas «por el reconocimiento del derecho de acceso a la información como un derecho fundamental» acceso en https://www.access-info.org/es/frontpage-es/27052

$147 \mathrm{Al}$ momento de cerrar estas páginas se tramita una importante reforma de la ley a través de la Proposición de Ley Integral de Lucha contra la Corrupción y Protección de los Denunciantes presentada por Ciudadanos, que incluye diversas mejoras. 